\title{
Cneo Pompeyo hijo en Hispania antes de la batalla de Munda
}

\author{
LUIS AMELA VALVERDE *
}

\begin{abstract}
RESUMEN ABSTRACT
Uno de los periodos peor conocidos y menos tratados de las guerras civiles

que azotaron Hispania durante el siglo । a.C. fue la actividad de Cneo Pompeyo hijo previa a la campaña de Munda (45 a.C.). El presente articulo intenta ofrecer una visión coherente de los hechos.

One of the periods worse known and less treaties of the civil wars that flogged Hispania during the I century B.C. it was the activity of Cnaeus Pompeius Magnus, elder son of Pompey, previous to the campaign of Munda (45 B.C.). The present anticle attemps to offer $a$ coherent vision of the facts.
\end{abstract}

\section{INTRODUCCIÓN}

La pésima gestión de Q. Casio Longino (tr. pl. 49 a.C.), gobernador cesariano de la Hispania Ulterior, más la importante corriente de simpatía a favor de la causa pompeyana, propició un levantamiento en contra suya en el año 48 a.C. ${ }^{1}$ César, para intentar arreglar la situación, envió al procónsul C. Trebonio (pr. 48 a.C., cos. suff. 45 a.C.) como sustituto de Casio Longino (BAlex. 64, 2. Dio Cass. $43,29,1)^{2}$. Este último se ve asi forzado

\footnotetext{
* Universidad de Barcelona.

- Sobre este tema, consúltese: M. A. MARiN DIAZ, "En torno a la conjura contra Q. Casio Longino", en Actas del II Congreso Andaluz de Estudios Clásicos I (Málaga, 1987), 185190.

Romaneli, 1959, 117. Rodriguez NeILA, 1988, 245. Ferreiro, 1993, 405 considera que Trebonio debió llegar a la provincia a principios del año 47 a.C. Por su parte, Dı́unoN, 1999,
} 
a marcharse y, evitando entrar en Corduba, centro de la rebelión, embarca en Malaca con todos los bienes que había logrado reunir producto de sus rapiñas y extorsiones, y finaliza su aventura naufragando y ahogándose frente al delta deil Ebro (BAlex. 64, 1-3. Dio Cass. 42, 16, 2).

La situación era delicada para Trebonio: la sublevación contra Casio Longino había agrupado, no sólo a la parte más veterana de su ejército (formada por las antiguas legiones varronianas, la II y la Vernacula), sino también a un buen número de ciudades (BAlex. 62, 2. Dio Cass. 43, 29, 1). Pero, con la sustitución del gobernador, los ánimos se tranquilizaron, puesto que las comunidades sublevadas se sometieron de manera inmediata a Trebonio y tanto los soldados como los pirovinciales permanecieron tranquilos durante un tiempo (Dio Cass. 43, 29, 1). En realidad, se trataba de una sumisión más aparente que real. La batalla de Pharsalus había destruido el ejército pompeyano y desmoronado al partido senatorial, por lo que no existían demasiadas alternativas para los rebeldes ${ }^{3}$.

Cicerón, en Roma, siempre bastante bien informado ${ }^{4}$, en una carta del ocho de marzo del año 47 a. C. (Cic. Att. 11, 12, 3) ${ }^{5}$, da a Hispania perdida a César, pues se había unido al África, que se encontraba en manos del bando republicano. Esta impresión ya la manifestaba en una carta del diecinueve de enero (Cic. Att. 11, 10, 2). Por tanto, a pesar de la paz reinante, ésta era sólo aparente. De hecho, cuando las circunstancias coyunturales existentes cambiaron, también lo hicieron los ánimos ${ }^{6}$.

Indudablemente, Cicerón debe referirse a los conatos de la sublevación contra Casio Longino, que Trebonio todavía no habia podido controlar completamente, posiblemente por llevar poco tiempo al frente de la provincia. Es interesante la mención de Cicerón que sea «Hispania» (y no la Bética, o la Ulterior) la que esté contra César. No se puede dilucidar si se trata de una exageración de las fuentes de Cicerón o en realidad el movimiento opositor fue mucho más importante de lo que las fuentes literarias reflejan.

\footnotetext{
XXII considera que sería en diciembre del 48 a.C. o enero del 47 a.C. (febrero del año 47 a.C. según el calendario oficial, como CANFORA, 1999, 466).

3 Rodriguez NeILA, 1988, 245. FerReiro, 1993, 406.

4 Pero en una carta de fin del año 46 a.C. señala que no sabe nada nuevo ni cierto de Hispania (Cic. Fam. 15, 18, 2). En una carta de enero del año 45 a.C. (Cic. Fam. 6, 18, 2) da noticias sobre al situación de Hispania, y en otra del mismo mes señala la existencia de rumores, anónimos, sobre la situación (Cic. Fam. 15, 17, 3). Su interés por lo que ocurre en Hispania es patente (Cic. Fam. 15, 19, 4), carta quizás de enero del año 45 a.C., en otra de 19 marzo del 45 a.C. pregunta por noticias sobre la guerra en Hispania (Cic. Att. 12, 23, 1). En una carta de febrero del 45 a.C. (Cic. Fam. 9, 13, 1) da datos (vid infra).

s. FERREIRO, 1993, 406 ก. 46.

6 HoRst, 1981, 332 considera que Trebonio no estaba a la altura de las circunstancias.
} 
Sea como fuere, al conocerse en la Ulterior la importancia de la resistencia africana ${ }^{7}$, las ciudades ${ }^{8}$, temerosas de las posibles represalias de César, enviaron secretamente emisarios a $Q$. Cecilio Metelo Pío Escipión Nasica (cos. 52 a.C.), comandante en jefe de las fuerzas senatoriales, expresándole el deseo de cambiar de partido (Dio Cass. 43, 29, 2), pues era el único capaz de ofrecer una asistencia eficaz ${ }^{9}$. Por supuesto que, aparte de las poblaciones, los individuos más directamente implicados en los acontecimientos del año 48 a.C. y los soldados de las legiones sublevadas estarían también en comunicación con las fuerzas opositoras a César.

\section{CNEO POMPEYO HIJO}

$\mathrm{Ni}$ que decir tiene que, para los jefes republicanos de África, era una tentación abrir un nuevo frente contra César. Se podía así repetir la situación del año 49 a.C. ${ }^{10}$, en que César se vio amenazado por sus adversarios por una maniobra en doble tenaza desde Hispania e Italia, sustituidas en este caso por Hispania y África ". Por ello, se decidió enviar un pequeño contingente para catalizar la rebelión.

El mando de las fuerzas recayó en una persona que si bien no tenía experiencia ni había detentado cargo político alguno (únicamente dirigió un escuadrón de barcos egipcios durante la campaña del año 49/48 a.C. [App. BCiv. 2, 71. Caes. BCiv. 3, 4, 4; 3, 5, 3; 3, 40, 1-5; 3, 111, 3. Plut. Ant. 25, 1; Cato min. 55, 3; Cic. 39, 1-2; Pomp. 62, 2], quizás como prefecto ${ }^{12}$ ), podía asumir perfectamente y con garantias de éxito la misión que se le iba a encomendar: Cneo Pompeyo hijo, que, como primogénito de Pompeyo Magno, podia aglutinar a todas las fuerzas contrarias a los cesarianos y dirigir a los descontentos ${ }^{13}$.

Dión Casio señala que Metelo Escipión y M. Porcio Catón Uticense ( $p r$. 54 a.C.) (el alma del ejército republicano) enviaron a Cneo Pompeyo hijo

A mediados del año 47 a.C. la resistencia republicana en África habia logrado tener una fuerza lo suficientemente considerable como para que en Roma se considerase como real la posibilidad de un desembarco (Cic. Att. 11, 15, 1; 11, 18, 1. Dio Cass. 42, 56, 4).

8 En el relato de Dión Casio, las ciudades son el sujeto de la oración.

FERREIRO, 1993, 406.

FerReIRo, 1993,407.

"Apiano (App. BCiv. 2, 87) señala que dos ejércitos considerables se preparaban contra César, uno en África y otro en Hispania.

12 BROUGHTON, 1952, 271 y 284.

13 Solana y Montenegro, 1986, 136-137. Ferreiro, 1993, 407. 
en respuesta a las peticiones llegadas de Hispania (Dio Cass. 43, 29, 2) ${ }^{14}$, ya que, al tener conocimiento de que el país se había sublevado, creyeron que los habitantes del país lo acogerían con entusiasmo, como hijo de Pompeyo Magno (Dio Cass. 42, 56, 4). En realidad, la elección no debió de ser tarea fácil, pues el mando de las fuerzas invasoras fue rechazado por L. Afranio (cos. 60 a.C.) y M. Petreyo (pr. 64 a.C.?) (Liv. Per. 113, 3), antiguos legados de Pompeyo Magno en la Península Ibérica, y que habían sido derrotados en llerda por César (49 a.C.) ${ }^{15}$. Por tanto, alguna otra poderosa razón hizo asignar la dirección de la expedición a Cneo Pompeyo hijo.

Catón de Útica amonestaba a Cneo Pompeyo hijo con discursos (BAfr. $22,1)^{16}$, en los cuales le hablaba sobre los diferentes méritos de su padre y le animaba a imitarle, recordándole que Pompeyo Magno no contaba con antepasados de eminente prestigio ni con extensas clientelas (BAfr. 22,4 ), al contrario que él (BAfr. 22, 5) ${ }^{17}$, a las cuales podría pedir ayuda para sí mismo y para la República ${ }^{18}$.

La alusión, en un primer momento, puede parecer que Cneo Pompeyo hijo intentase levantar un ejército en África o en Sicilia, pero varios investigadores ${ }^{19}$ han situado más correctamente que se está ha-

14 En esta cita Dión Casio señala que Cneo Pompeyo hijo fue enviado con otros a Hispania, pero no se puede precisar quiénes eran éstos.

is Esta negativa es especialmente llamativa en el caso de Afranio, pues ya anteriormente había participado en la guerra sertoriana, e incluso habia sido gobernador de la Hispania Citerior durante los años 71 a 67 a.C. Consúltese: C. F. KONRAD, "Afranius imperator", HAnt 8,67-76.

16 Sobre este capítulo del Bellum Africanum, puede consultarse: A. PALLAVISINI, «Il capitolo 22 del Bellum Africum e la propaganda augustea", en Contributi dell'stituto di Storia Antica II. Propaganda e persuasione occulta nell'antichità (Milano, 1974), 107-114.

Muy posiblemente son estas paternae clientelae, a las que alude Catón de Útica, los responsables del gran recibimiento que recibió Cneo Pompeyo hijo en Hispania, como muestran tanto los denarios emitidos a su nombre así como las fuentes literarias (Dio Cass. 43, 30, 1).

${ }_{18} M$. Cato interim, qui Vticae praeerat, $C n$. Pompeium filium multis verbis assidueque obiurgare non desistebat. Tuus, inquit, pater istuc aetatis cum esset, et animaduertisset rem publicam ab nefariis sceleratisque civibus oppressam, bonosque aut interfectos aut exilio multatos patria civitateque carere, gloria et animi magnitudine elatus, privatus atque adulescentulus, paterni exercitus reliquiis collectis, paene oppressam funditusque deletam Italiam urbemque Romanam in libertatem vindicavit, idemque Siciliam Áfricam Numidiam Mauretaniam mirabili celeritate armis recepit. Quibus ex rebus, sibi eam dignitatem quae est per gentes clarissima notissimaque conciliavit, adulescentulusque atque eques Romanus triumphavit. Atque ille, non ita amplia rebus patris gentis, neque tam, excellenti dignitate maiorum parta, neque tantis clientelis nominisque claritate praeditus, in rem publicam est ingressus. Tu contra, et patris nobilitate et dignitate, et per te ipse satis animi magnitudine dilingetiaque praeditus, nonne eniteris, et proficosceris ad patemas clientelas, auxilium tibi reique publicae atque optimo cuique efflagitatum? (BAfr. 21, 1-5).

19 HADAS, 1930, 52. Wilson, 1966, 37. GelzER, 1969, 93. HARMAND, 1970, 188. Diouron, 1999, XXII. 
blando de la Península Ibérica ${ }^{20}$. Así, si se analiza con atención el texto, se deduce que Catón de Útica estaba incitando a Cneo Pompeyo hijo a acudir a Hispania, a la que, desde luego, no se menciona, pero los acontecimientos posteriores demuestran que éste era el objetivo que se perseguía, puesto que poco después Cneo Pompeyo hijo se dirigió a ella (BAfr. 23, 1-3).

La situación militar del momento hace pensar igualmente en este territorio, pues el mal gobierno de Q. Casio Longino y las intrigas de los partidarios de la causa pompeyana habian ocasionado la sublevación de la Bética contra César. Y es en la Península lbérica donde Pompeyo Magno tenía la clientela más adicta a su persona y a su memoria. Por ello, no es extraño que se enviase a su hijo mayor de Pompeyo, en donde se esperaba que todas las ciudades que habian luchado a su favor durante la época de Q. Sertorio, participasen en la causa anticesariana ${ }^{21}$.

Un apoyo a la presunción de que la anterior cita viene a referirse al caso hispano viene sin duda gracias a la mención por parte de Dión Casio (Dio Cass. $41,18,3 ; 42,56,4$ ) del envío por parte de los pompeyanos de África a Cneo Pompeyo hijo pues, sabiendo que el país se encontraba en rebeldía, se pensó (muy acertadamente, como los hechos demuestran posteriormente), que sería bien recibido como hijo de Pompeyo Magno, sobre todo por parte de los clientes de su familia ${ }^{22}$, como refleja el Bellum Áfricanum (BAfr. 22, 2-5). Cneo Pompeyo hijo, ya en la Península Ibérica, logró la adhesión de gran número de ciudades, tanto debido a las exacciones de los gobernadores cesarianos, como al buen recuerdo que tenian de su padre, por lo que esperaban mucho de él (Dio Cass. 43, 30, 1-1 45, 10, 1. Vel. Pat. 2, 55, 2). De hecho, la versión del Bellum Africanum, partidista, pretendía minimizar los sentimientos filopompeyanos de Hispania ${ }^{23}$.

\section{EL VIAJE}

Cneo Pompeyo hijo preparó en la ciudad de Utica, capital de la provincia de África y centro de la resistencia senatorial, una flota de treinta

20 Otros investigadores creen que estas paternas clientelas serian las de Pompeyo Magno en el Piceno, como así señala Ooteghem, 1954, 52.Sayas, 1989, 112, 36. Scuderi, 1989, 134, o de la propia África, como hace SYME, 1989, 199.

21 ROSSI, 1953, 293. HARMAND, 1970, 198.

2. Schulten, 1940, 94. Thouvenot, 1973, 144. Rodriguez NeIla, 1988, 252. Lintott, 1993, 169.

2 GabBa, 1970, 140. Diouron, 1999, XXII n. 20. 
naves de todas clases, pocas de ellas con espolón (es decir, militares), a la que ajuntó una tropa ligera formada por dos mil esclavos y hombres libres, unos armados y otros desarmados (BAfr. 23, 1); unas fuerzas bastante escasas ${ }^{24}$. Esta escuadra zarpó desde Utica en dirección a Mauritania (BAfr. 23, 1), con la evidente intención de dirigirse a Hispania ${ }^{25}$.

En territorio perteneciente al rey Bogud (quien, como su hermano Bocco II, era filocesariano), Cneo Pompeyo hijo decidió asaltar la ciudad de Ascurum ${ }^{26}$, en la que exístía una guarnición del monarca (BAfr. 23, 1). Los defensores dejaron avanzar a las tropas pompeyanas hasta las mismas puertas y murallas, momento en que hicieron una salida y derrotaron con esta maniobra sorpresa a los invasores, que huyeron a la desbandada, persiguiéndolos hasta incluso sus propias naves (BAfr. 23, 2). Con este mal suceso, Cneo Pompeyo hijo se apartó allí con sus naves y sin tocar en ningún otro punto de la costa dirigió su escuadra rumbo a las Baleares (BAfr. 23,3). No se arriesgó a intentar una nueva empresa de este género ${ }^{27}$.

Más difícil es conocer cuándo Cneo Pompeyo hijo partió hacia Hispania y llegó a sus costas. Las fuentes son divergentes en este sen-

24 Rossi, 1953, 293. Gsell, 1928, 29 n. 4 y 45. CARCopino, 1968, 458 consideran que las fuerzas de Cneo Pompeyo hijo serían respetables, ya que se incluian Alóbroges (sin duda los jinetes) que Juba había hecho prisioneros después de derrotar a C. Escribonio Curión (tr. pl. 50 a.C.) en el año 49 a.C. (Dio Cass. $43,30,3$ ), to que no plantea ninguna duda, puesto que estas tropas ya figuran mencionadas antes de la llegada de los supervivientes de Thapsus. Más complicado es aceptar que en este mismo contingente invasor figurasen tropas que, desde Hispania, habian ido a Grecia con L. Afranio (uno de los legados de Pompeyo Magno en la Peninsula Ibérica al comienzo de la guerra civil) para participar en Pharsalus (Caes. BCiv. 3 , 88, 3), y que luego habian podido huir a África, y formasen posteriormente una legión durante la campaña de Munda (BHisp. 7, 4), desembarcando con Cneo Pompeyo hijo; más bien, este último contingente debió llegar a Hispania en el año 46 a.C., con el resto de las fuerzas republicanas que pudieron huir después del combate de Thapsus, puesto que el Bellum Hispaniense informa claramente que esta unidad, mandada por Afranio, procedia de África.

25 Esta ruta ya fue seguida en el año 62 a.C. por $P$. Vatinio, quien al dirigirse a Hispania por via marítima pasó por Sardínia, el reino de Hiempsal II de Numidia (occidental) y el de Mastanesoso de Mauritania (Cic. Vat. 5, 12).

26 Gsell, 1928, 46. Romanelli, 1959, 121 n. ${ }^{\circ}$ 1. Carcopino, 1968, 458 señalan que una ciudad denominada Ascurum es desconocida. Se ha supuesto que pudiera identificarse con Rusuccurru pero, en tal caso, estaria en territorio de Bocco Il, no en el de Bogud. El rio Mulucha era la frontera entre los dos reinos mauritanos. GozALBES CRAVIOTO, 1994, 292 considera que se trata de Rusaddir, la actual Melilla. Es mucho mejor, en este caso, Rusuccurru, pues desde este puntó las islas Baleares se encuentran justamente en dirección Norte, mientras que Rusaddir se encuentra excesivamente escorada al Oeste. Sobre Russadir, consúltese: R. GutiERREz GonzalEz: "Russadir, Visión actualizada", ETF serie II, 10 (1997) 387-402.

27 ROMANELLI. 1959, 121. 
tido, e incluso alientan la confusión ${ }^{28}$. Apiano (App. BCiv. 2, 87) y el Bellum Hispaniense (BHisp. 1, 1) no ofrecen utilidad alguna ${ }^{29}$. El Bellum Africanum menciona su partida después de haberse referido a los primeros hechos de armas de César en África, es decir, principios del año 46 a.C.; pero los capítulos en que se cita este episodio (22-23) son claramente atemporales. Dión Casio señala que la partida de Cneo Pompeyo se produjo durante la estancia de César en Egipto (Dio Cass. $42,56,4)^{30}$, es decir, en el primer semestre del año 47 a.C. Livio (Liv. Per. 113,3$)$ recuerda que la llegada de Cneo Pompeyo hijo a Hispania fue anterior a la derrota del rey Farnaces II, rey del Ponto, en la batalla de Zela (2 de agosto del año 47 a.C., 12 de junio en el calendario juliano), o sea, en los primeros meses del segundo semestre del año 47 a.C.

Ferreiro considera que Cneo Pompeyo hijo zarparía de Utica, a comienzos de noviembre del año 47 a $C .{ }^{31}$, al considerar que los líderes republicanos de África no atendieron las peticiones provenientes de Hispania, debido a que estaban más interesados en sus propios preparativos para repeler una eventual invasión de César. Cuando éste último volvió a Italia (24 de septiembre del año 47 a.C., 24 de julio del calendario juliano), después de sus campañas en Alejandría y contra Farnaces II, fue cuando decidieron crear un nuevo frente en la Península lbérica, pues en buena lógica César no tardaría en atacarles ${ }^{32}$.

La opinión de la llegada tardía de Cneo Pompeyo hijo parece fundamentarse en una carta de Cicerón (Cic. Att. 12, 2, 1), fechada quizás en el mes de abril del año 46 a.C. (comienzos de febrero del calendario juliano), en la que se rumoreaba que Cneo Pompeyo hijo no aparecía y que nunca

28 ROMANELLI. 1959,120 n. 2.

29 GSEll. 1928, 33 n. 1. PASCuCC. 1965, 118. DIOURON. 1999, XXIII n." 24 señalan que Apiano dice, por error, que Cneo Pompeyo hijo y $T$. Labieno se dirigen desde Corcyra, a donde habian liegado después del desastre de Pharsalus (9 de agosto del año 48 a.C., 28 de junio en el calendario juliano) a Hispania, lo que es falso: la mención de Escápula es, en este sentido, clarificativa. También se puede interpretar por el Bellum Hispaniense que fue después de la derrota $M$ rey Farnaces II de Ponto y de la batalla de Thapsus (Affica recepta, 6 de abril del año 46 a.C., 6 de febrero del calendario juliano), 10 que tampoco es cierto, a pesar de que asi lo crea Pascucci, al igual que CANFORA. 1999, 264 y 469

3) Gelzer, 1969, 255. ÉtIENNE, 1997, 141 señalan que César partió de Egipto a fines de junio del año 47 a.C. (principios de mayo según el calendario juliano).

i1 FERREIRO. 1993, 407. CARCOPINO. 1968, 458, a quien Ferreiro sigue, a fines del año 47 a.C., como CANFORA. 1999, 263. KNAPP, 1983, 25, más reservado, a mediados del mes de marzo del año 46 a.C., aprovechando el inicio de la estación favorable a la navegación.

3: FERREIRO, 1993, 406-407. DIOURON, 1999, XXIII n. 24. Los meses de octubre y noviembre del calendario oficial corresponden a la estación del verano. 
estuvo en las islas Baleares ${ }^{33}$ como afirmaba Pacieco (quien realmente tenía razón) ${ }^{34}$.

Más bien, hay que considerar que sería a fines del año 47 a.C. cuando Cneo Pompeyo hijo llegaría a Hispania ${ }^{35}$. Las imponentes fuerzas militares que reunió para la campaña de Munda (vid infra) difícilmente pudo conseguirlas en unos pocos meses. La mención de Apiano de la existencia de: "y así dos ejércitos considerables se preparaban contra César, uno en África y otro en Hispania" (App. BCiv. 2, 87), de manera simultánea, no uno después del otro, parece señalar que el movimiento pompeyano en la Península Ibérica es anterior a la campaña de César en África. Igualmente, Plutarco señala que, durante la estancia de Catón de Útica en África, "Hispania habia hecho defección para pasarse al hijo de Pompeyo" (Plut. Cato min. 59, 9).

Por tanto, parece razonable concluir que, al mismo tiempo, tanto en África como en la Península Ibérica los opositores a César habían preparado sendos ejércitos. De otra manera, sería ininteligible las fuentes de las que se dispone. La datación de una acuñación local de Carthago Nova en el año 47 a.C. (RPC 149. CNH Cartagonova 4-5), en la que se menciona a Cneo Pompeyo hijo, parece confirmar que ya en este año éste se encontraba en tierras ibéricas.

\section{LA LLEGADA A HISPANIA}

Cneo Pompeyo hijo, procedente de Mauritania, tomó las islas Baleares ${ }^{36}$ sin combate, a excepción de Ebusus, a la que ocupó con dificultad (Dio

\footnotetext{
33 FerReiro, 1993, 407 considera que el periodo de enfermedad de Cneo Pompeyo hijo en las islas Baleares (Dio Cass. $43,29,2$ ) fue de varios meses, para poder asi fechar la llegada de éste a territorio peninsular en el segundo semestre del año 46 a.C., un tiempo excesivamente largo. Dión Casio dice que Cneo Pompeyo hijo "se quedó alli algún tiempo".

34 SCHULten. 1940, 97. PASCUCCI. 1965, 149. SKACKLETON-BAILEY, 1966, 269. GonzAlez Román y Marin Diaz, 1981-1985, 29. González Román. 1986-1987, 73. Caballos Rufino, 1989, 260-261. Diouron, 1999, 56 lo identifican con L. Vibio Pa(c)cieco, partidaro de César en la Bética (BHisp. 3 , 4), posiblemente hijo del mismo nombre que en el año 87 a.C. hospedó a L. Licinio Craso (Plut. Crass. 4, 2) y combatió a Q. Sertorio (Plut. Sert. 9, 2-3). Sobre la posible autoría de este personaje del Bellum Hispaniense, consúltese: F. STROCCHI, "L'autore del Bellum Hispaniense", R/L 130 (1996), 99-112. Sobre esta familia: J. S. Hernandez Fernandez, "Los Víbií Pac(c)iaeci de la Bética: una familia mal conocida", Faventia 20 (1998), 168-174.

35 Schulten, 1940, 94. Beltran Martinez, 1952, 16. Blazouez, 1975, 100 y 179. Rodriguez NEILA, 1988,251.

36 HAMBLENNE, 1973, 636 n. 18 considera que un verso del Fullo de Laberio (Laber. apud Non, p. 307, 21) alude a la "locura" de $\mathrm{Cn}$. Pompeyo hijo de dirigirse a las islas Baleares: utrum tu hunc gruem Balearicum, an hominem putas esse?
} 
Cass. $43,29,2)^{37}$. La situación estratégica de esta isla es evidente, como muestra el interés de tenerla bajo su control durante las dos guerras civiles, puesto que esta población e isla ya había sido conquistada anteriormente (81 a.C.) por el mismo Q. Sertorio (Plut. Sert. 7, 3), y cuyas aguas fueron testigo de un combate naval entre éste y el gobernador silano $\mathrm{C}$. Annio (Plut. Sert. 7, 4). Cneo Pompeyo hijo cayó enfermo, por lo que estuvo alli algún tiempo con sus soldados (Dio Cass. 43, 29, 2).

Dión Casio señala que, al conocerse la noticia de la demora de Cneo Pompeyo hijo, los soldados de "Hispania" (entiéndase la Ulterior), que se habian enterado de la muerte de Metelo Escipión y de que C. Didio, legado cesariano encargado del mando de la flota en el Mediterraneo Occidental, navegaba contra ellos, temieron ser aniquilados antes de que llegase Cneo Pompeyo hijo (Dio Cass. 43, 29, 3). En consecuencia, no lo esperaron ${ }^{38}$, y las tropas amotinadas pusieron a su frente a $T$. Quincto Escápula y Q. Aponio, caballeros romanos, expulsan a Trebonio de la provincia, y provocan el levantamiento de toda la Bética ${ }^{39}$ (Dio Cass. 43, 29, 3).

Estas tropas no pueden ser más que las antiguas legiones varronianas ${ }^{40}$ (Caes. BCiv. 2, 18, I), que no fueron disueltas por César, como sus homólogas de la Citerior. El mismo Bellum Hispaniense indica que entre las unidades militares que tenían valor entre los pompeyanos se encontraba las dos legiones Vernacula et Secunda, quae a Trebonio transfugerant (BHIsp. 7, 4).

Desde luego, si se tiene en cuenta que la flota de Didio zarpó de la isla de Sardinia (Cerdeña) en el mes de junio (abril del calendario juliano) del año 46 a.C. (sobre la base de BAfr. 98, 2) ${ }^{41}$, difícilmente Cneo Pompeyo hijo pudo llegar a la Península en el año 47 a.C., si se toma al pie de la letra el relato de Dión Casio. Por esta causa, Ferreiro considera que los sublevados expulsaron a Trebonio en el mes de agosto del año 46 a. C. ${ }^{42}$.

\footnotetext{
37 GSELL. 1928, 45 n. 2 considera la llegada de Cneo Pompeyo hijo a las Baleares en el mes de enero del año 46 a.C. Pero se trata de una fecha muy tardía.

38 FERREIRO. 1993, 408 señala que las circunstancias habian cambiado: no se trata de reforzar la resistencia republicana en Átrica, sino de enfrentarse solos a César.

39 Dión Casio especifica que no se trata de Hispania o de la provincia Ulterior, sino concretamente de la región de la Bética, por lo que es de suponer que al menos la Citerior estaba en manos de los partidarios de César.

40 PASCUCC1, 1965, 191.

41 Schulten, 1940, 146. Gelzer, 1968, 293. Canfora, 1999, 470. Diouron, 1999. XXIV-XXV n. 28 .

12 FERREIRO, 1993,408-409. SHACKLETON-BAILEY, 1966, 281 considera que fue hacia el mes de junio del año 46 a. C.
} 
Ferreiro considera que las noticias de la partida de la escuadra de Didio desde Sardínía llegó a Hispania a finales de julio del año 46 a. C. ${ }^{43}$, al mismo tiempo que César regresaba a Roma. Por tanto, César no podía conocer la sublevación de las legiones, el nombramiento de Escápula y Aponio, y la posterior expulsión de Trebonio hasta algún tiempo después, quizás en el mes de septiembre. De esta forma, al menos hasta finales del mes de septiembre o incluso más tarde cuando fuerzas cesarianas de refuerzo, al mando de $Q$. Fabio Máximo, desembarcarían en Hispania. Sería en el mes de septiembre oficial (la estación de primavera) cuando Cneo Pompeyo hijo ya restablecido de su enfermedad, y enterado de lo acontecido en la Hispania Ulterior, cruza a la Península, asedia y toma Carthago Nova, y se dirige hacia mediodía, donde se le unen los jefes republicanos y parte de las tropas republicanos supervivientes de Thapsus e inicia un auténtico paseo triunfal por la zona ${ }^{44}$.

Pero, es de destacar que Dión Casio, al referirse a la partida de la escuadra de Didio, señala que César conocía las actividades de Cneo Pompeyo hijo en Hispania y que, juzgando (erróneamente) que sería fácil de vencer, envió primero a Didio con su flota y posteriormente tropas recién reclutadas a combatirle por medio de sus lugartenientes (Dio Cass. $43,28,1$ ), quienes sin duda deben ser ${ }^{45} \mathrm{Q}$. Pedio (pr. 48 a C.) ${ }^{46} \mathrm{y}$

a's Étienne, 1997, 147 señala que César llegó a Roma exactamente el 25 de julio (25 de mayo según el calendario reformado).

44 Ferrelro. 1993, 409. DIOURON. 1999, XXV. Se pretende así justificar la cita al respecto del Bellum Hispaniense (BHisp. 1, 1).

45 SCHULTEN, 1940. 146. Se trata de los dos personajes que se nombran a continuación, pues si no fuera asi seria difícil explicar su presencia en Obulco a la llegada de César para iniciar las operaciones de la campaña de Munda (BHisp. 2, 2. Dio Cass. 43, 31, 1. Str. $3,4, g)$

Ferreiro, 1993, 407 considera que Pedio, sobrino nieto de César (Suet. Caes. 83, 2), gobernó la provincia de Hispania Citerior, como promagistrado, en sustitución de Lépido ( $p r .49$ a.C., cos 46 a.C.), desde comienzos del año 46. En cambio, SCHULTEN. 1940, 93 y 96 cree que sería el gobernador de la Hispania Ulterior en los años 47-46 a.C., al considerar que Fabio Máximo lo sería de la Hispania Citerior, sobre la base del hallazgo en el NO. peninsular de unas inscripciones en su honor, que en realidad no le corresponden (vid infra). Por su parte, DIOURON, 1999, 52 lo considera gobernador de la Hispania Ulterior cuando estalló la sublevación de Escápula y Aponio.- CARCOPINO, 1968, 459. ROLUAN. 1978a, 169. SOlAnA y MONTENE. GRO. 1986, 137 ofrecen una explicación diferente, pues creen que César, tras desembarcar en Cerdeña a su vuelta de África, envió desde allí a Hispania a Q. Pedio (y Fabio Máximo) al mando de algunas tropas. FERREIRO, 1993, 408 señala que, efectivamente, las fuentes no dicen nada sobre este particular, pero sostiene que Pedio sería enviado a la Hispania Citerior mucho antes, cuando César regresó a Italia desde Oriente. Su designación se produciría en el mes de octubre del año 47 a.C., recién llegado César a Roma, momento en que se repartieron las provincias, con el fin de sustituir a M. Emilio Lépido, que dejaba vacante. la provincia para el año 46 a.C. Sobre este personaje, consúltese: A. KEAVENEY y J. MADDEN. "Lucius Pinarius, Quintus Pedius», Latomus 47 (1988), 354-357. 
Q. Fabio Máximo (pr. 48 a.C.?, cos. suff. 45 a. C.) ${ }^{47}$. Pero, cuando César supo los grandes progresos de Cneo Pompeyo hijo y que las fuerzas enviadas no eran capaces de hacerle frente, sin hacer nada, decidió entonces dirigir personalmente la campaña (Cic. Att. 12, 7, 1; 12, 8, 1. Dio Cass. $43,28,2 ; 43,31,1)$ a fines del año 46 a.C.

Por tanto, es forzoso considerar que los hechos no ocurrieron exactamente de la forma que narra Dión Casio. La sublevación de Escápula y Aponio quizás aconteciera ya en el mismo año 47 a.C., y la reacción cesariana no empezaría hasta mediados del año siguiente, pues era más importante someter las fuerzas senatoriales concentradas en África, que amenazaban Sicilia e Italia. No hay que olvidar que Sicilia y África eran los graneros de la Roma republicana (Egipto es un estado independiente, al menos en teoría), mientras que Hispania Ulterior no ofrecia un peligro inmediato a las autoridades de Roma, debido a que se interponia la Hispania Citerior y la Galia.

Es difícil suponer que las tropas al mando de Escápula y Aponio se sublevaran tan tardíamente durante el mes de agosto del año 46 a.C., eliminada la resistencia africana, como considera Ferreiro ${ }^{48}$. Dada la correlación de fuerzas, de ser asi no era más que una invitación al suicidio, a no ser que Cneo Pompeyo hijo ya estuviera en la Península desde mucho tiempo antes y hubiera asentada su posición, lo que es incompatible en principio con las fuerzas cesarianas en Hispania, que al menos algo tendrian que decir.

En la Hispania Ulterior habia que contar al menos con las dos antiguas legiones de Varrón (la 11 y la Vernacula), que habían protagonizado la sublevación contra Casio Longino, más las legiones reclutadas por los cesarianos en el año 49 a.C. y enviadas a la Península a Casio Longino (la $X X I$ y la $X X X$ ), más la levantada por este último (la $V$ ), amén de los auxiliares correspondientes. En este mismo sentido, también habría que contar

\footnotetext{
47 Tovar y BlazQuez, 1975, 106. Roldan, 1978a, 169. Ferreiro, 1993, 408-409 consideran que durante el año 46 a.C. Trebonio siguió siendo el gobernador de la Uiterior, hasta que fue expulsado por los sublevados, y sustituido por Fabio Máximo, como promagistrado. Que fue este personaje, y no Pedio, el gobernador de la Ulterior, puede inferirse porque continuó las operaciones en la Ulterior después de celebrarse la batalla de Munda. SCHULTEN, 1940, 96-97 (seguido por MAÑANES, 1981, 416. DIOURON. 1999, 53) señala dos (en realidad tres) epígrates encontrado en Gallaecia, dos en Lucus Augusti (CIL $112581=$ IRG $1154=$ ILER 1019 y $6024=$ IRPL 19. HAEp 311 y $1726=$ IRG $1155=$ ILER $1020=$ IRPL 20) y otro en Bracara Augusta (EE VIH, $504=I L E R$ 1028 = ILS 8895), que atribuyen a Q. Fabio Máximo, como gobernador de la Hispania Citerior, pero que en realidad son de su hijo P. Fabio Máximo (cos. 11 a.C.), gobernador de la Hispania Tarraconense (c. 4- 1 a.C.), como señala claramente su praenomen: ARIAS, LE ROuX y TRANOY. 1979, 43-44. TRANOY, 1981, 149.

48 FERREIRO 1993, 409
} 
con las fuerzas de la Hispania Citerior (Carthago Nova está dentro de esta última demarcación), que en época de M. Emilio Lépido (año 48 a.C.), estaba formada al menos por cuatro legiones, que es lo que se supone que tendría su sucesor, Pedio ${ }^{49}$.

Es difícil considerar que tan numerosas fuerzas permitiesen maniobrar de semejante manera, y a tal velocidad, a Cneo Pompeyo hijo, a no ser que su número hubiera sido disminuido para acudir a otros frentes o que la situación dentro de Hispania no fuera la de una apacible calma y tranquilidad, como parece sugerir el silencio de las fuentes. Quizás las causas que originaron que numerosos gobernadores celebrasen durante la década de los años treinta triunfos ex Hispania ${ }^{50}$ existían ya en este momento, es decir, sublevaciones indígenas que se desconocen por completo.

Sea como fuere, Dión Casio dice que Cneo Pompeyo hijo, restablecido de su enfermedad, cruzó el mar hacia la Penínsular ${ }^{51}$, donde enseguida tomó algunas ciudades sin resistencia, debido a que estaban irritadas contra los gobernadores (cesarianos) y esperaban mucho de él debido al recuerdo de la memoria de su padre, Pompeyo Magno (Dio Cast. $43,30,1)$. De esta forma, puso sitio a Carthago Nova ${ }^{52}$, que se resistía a tratar su entrega (Dio Cass. 43, 30, 1). Las fuerzas al mando de Escápula, al conocer su llegada, acudieron alli y le proclamaron imperator ${ }^{53}$, después de lo cual le guardaron siempre la mayor fidelidad y le sirvieron con el mayor celo, considerando como propios sus éxitos y sus reveses; con lo que se robusteció su determinación de obtener aquellos y evitar éstos (Dio Cass. 43, 30, 2). Cneo pudo comprobar que la provincia estaba de parte del Senado y de los enemigos de César ${ }^{54}$.

49 BRUNT, 1971, 475. ROLdÁ, 1972, 103. FERREIRO, 1993, 402 y 408 consideran que, para el año 48 a.C., la Hispania Citerior tendría los mismos efectivos que la Hispania Ulterior, es decir, cuatro legiones: Lépido acudió desde su provincia a auxiliar a Casio Longino con 35 cohortes legionarias (BAlex, 63, 1). Posiblemente, las otras cinco cohortes (para formar el total de cuatro legiones), quedarian de guarnición.

50 Cn. Domicio Calvino en el año 36 a.C., C. Norbano Flaco en el año 34 a.C., L. Marcio Filipo en el año 33 a.C., Ap. Claudio Pulcher en el año 32 a.C.

51 RICHARDSON. 1998, 105 considera que Cneo Pompeyo hijo desembarcaria en la Península probablemente a comienzos del año 46 a.C., pero quizás seria más adecuado a finales del año 47 a.C.

52 BLÁZQUeZ, 1975, 100 y 179 considera que Cneo Pompeyo hijo desembarcó en esta población procedente de las islas Baleares, pero el testimonio de Dión Casio lo desmiente.

53 GaRCía GaRRIDO y LALANA, 191-1993, 103 señalan el hallazgo de glandes con leyenda $C N$ MAG / IMP en Urso (AE 1997 825), mismo epigrafe que su moneda de bronce RRC 471 (vid infra).

54 Solana y MONTENEGRo. 1986, 137. CANFORA, 1999, 264. 
El sitio de Carthago Nova ${ }^{55}$, y su posterior captura ${ }^{56}$, dio origen al cenit de Cneo Pompeyo hijo en Hispania. La importancia de esta ciudad en el SE. es evidente, por su magnífica situación y su extraordinario puerto, como lo pone de manifiesto que Sexto Pompeyo (hermano menor de Cneo Pompeyo hijo) la volviera a asediar posteriormente en el año 44 a.C. (Dio Cass. 45, 10, 3), y la utilizara de cuartel general (Cic. Att. 16, 4, 2). Igualmente, en el año 45 a.C., César se reunió aquí con el joven C. Octavio (quizás acompañado de M. Vipsanio Agripa) y administró justicia (Nic. Dam. 12).

Precisamente de Carthago Nova procede la citada acuñación local de bronce (RPC 149. CNH Cartagonova 4-5) ${ }^{57}$ fechada en el año 47 a.C. ${ }^{58}$, en cuyo anverso se menciona a $C$ (naeus) $P$ (ompeius) imp(erator) y figura una imagen de la Concordia que recubre en realidad el retrato de Pompeyo Magno. En el reverso figura un trofeo militar ${ }^{59}$ y se menciona al general pompeyano M. Munacio Sabino (monetario igualmente del denario de Cneo Pompeyo hijo RIRC 477 como proquaestor).

\footnotetext{
55 Sobre esta ciudad, consúltese: S. Ramallo et Alii, "Carthago Nova», DArch 10 (1992), $105-118$

56 CARCOPINO, 1968, 459. DIOURON. 1999, XXV señalan que Cneo Pompeyo hijo debió tomar
} Carthago Nova, debido a que el silencio del Bellum Hispaniense al respecto es significativo. La mención por Dión Casio de Cneo Pompeyo hijo como "strategos autocrator" (Dio Cass. 43, 30, 2) lo avala, asi como la acuñación de una emisión local en esta ciudad a nombre de éste, como ya se ha indicado

5? Su descripción es la siguiente: Semis de bronce de $22 \mathrm{~mm}$. de diámetro y $4.96 \mathrm{~g}$. de peso medio. Anv.: Cabeza velada y diademada, representando la Concordia (el cual parece tomado de los denarios de L. Emilio Lépido Paulo, RRC 41511), aunque el retrato en realidad es el de Pompeyo Magno; alrededor ALBINUS.HEL.POLLIO,II-Q(U). Rev.: Trofeo militar compuesto de coraza y casco sobre mástil nudoso, que corta la inscripción en tres líneas SABINUS - C. $M$. - IMP.

S8 Beltran Martinez, 1949, 16; 1952, 23. BlÁzQUeZ, 1975, 100. Villaronga. 1979, 246. AMELA. 1990-1991, 196. TSIRKIN. 1993, 285. El cálculo se basa en que se batía moneda en esta ciudad cada lustro, correspondiendo uno de estos años al 47 a.C. Si esto es correcto, sería una prueba concluyente de que Cneo Pompeyo hijo se encontraba en la Península en dicho año. Por este motivo, es corriente que se diga que Carthago Nova fue durante la guerra civil propompeyana, pero el doble asedio que recibió por parte de este bando muestra al menos que esta tendencia no era del todo unánime dentro de la población.

59 BeLtRAN MARTINEZ. 1949, 20. BLAZQUeZ, 1975, 98 sugieren que se trata de una representación de los Trofeos de Pompeyo ubicados en los Pirineos. Los hallazgos arqueológicos descartan que hubiera tenido la forma como aparece en la moneda. Sobre los Trofeos de Pompeyo, consúltese: G. CASTElivi, Panissars: Les trophées de Pompée \& la Vía Domitia. L'archéologie d'un site ou fflistoire retrouvée, Perpígnan, 1988. G. CAstellvi, J. M. NOLLA e 1. RodA, «Pompey's Trophies", en Actes XIV Congrés Intemacional d'Arqueologia Classica. La ciutat en el món romá. Vol. 2 Comunicaciones (Tarragona, 1994), 93-96; "La identificación de los trofeos de Pompeyo en el Pirineo", JRA 8 (1995), 5-18. L. AMELA VALVERDE, "Los Trofeos de Pompeyo", Habis 32 (2001), 185-202. Sobre la historiografia de este monumento, consúltese: G. CASTELLVI, "Localisation du trophée: essai d'historiographie, XIVern-XXe siécies", en Etudes Roussillonnaises á Pierre Ponsich (Perpignan, 1987), 491-503. 60. 


\section{EL PAPEL DE ESCÁPULA}

Dión Casio (Dio Cass. 43, 29, 3), al hablar de los acontecimientos del año 47 a.C., cita a un T. Quincto Escápula que fue, junto con Q. Aponio ${ }^{60}$, una de las dos cabezas de la revuelta de las legiones en Hispania en la Ulterior, calificándose a ambos como equites. Vuelve a aparecer cuando Cneo Pompeyo hijo sitiaba Carthago Nova, acudiendo alli con sus tropas (Dio Cass. 43, 30, 2), por lo que es deducible que sería uno de los generales pompeyanos en la Bética (App. BCiv. 2, 87). Cicerón lo califica como el provocador de la guerra en la región (Cic. Fam. 9, 13, 1) y el Bellum Hispaniense como totius seditionis caput (BHisp. 33, 3), lo que seguramente debió ser cierto ${ }^{61}$, y no un simple tribuno militar o prefecto ${ }^{62}$.

Indudablemente este personaje debe de ser el que promueve la resistencia pompeyana en Hispania, asumiendo todo el protagonismo (de Aponio nada más se sabe), y debe de haber tomado la iniciativa con las legiones sublevadas en el año 48 a.C. contra Casio Longino. El Bellum Alexandrinum menciona a un Annius Scapula participó en la conjuración contra Casio Longino (BAlex. 55, 2), siendo descrito como maximae dignitatis et gratiae provincialem hominem. Intimo de Casio Longino, fue condenado a muerte, pero como muchos se libraron de esta sentencia pagando dinero (BAlex. 55,4$)$ se desconoce si ésta se aplicó.

Generalmente se ha identificado a Annio Escápula y a T. Quincto Escápula (BAlex. 55, 2. Cic. Att. 12, 38, 2; 12, 40, 4) como un solo personaje ${ }^{63}$, perte-

60 Indudablemente debe tratarse de un caballero romano, al cual la mayor parte de los autores lo dan como de origen hispano (GONZALEZ ROMÁN. 1981, 199. KNAPP, 1983, 25. CABALLOS RU. FINO. 1989, 266; 1990, 75), quizás de Corduba, como señala Knapp, debido a que el nomen Aponius es muy frecuente en la epigrafía de la Bética, y llevado de la consideración de que la familia senatorial altoimperial de los Dillii era originaria de esta ciudad. Para NICOLET. 1966, 780 seria un rico romano (de origen samnita) establecido hace mucho tiempo en Hispania, y que también debió participar en la conjura contra Casio Longino.

${ }_{61}$ TSIRKIN, 1981, 81.

62 NiCOLET, 1966, 779-780. BROUGHTON, 1985, 180-BALIL no lo cita en su trabajo.

53 WiLson. 1966, 38. KinJapp. 1983, 25. Gonzalez Román y MARin Diaz. 1994, 246 señalan que Dión Casio o su fuente parece haber confundido el praenomen de $\mathrm{Q}$. Aponio con el nomen de Escápula, por lo que su nombre sería Annius Scapula. CABAllos Rufino, 1989, 266 y Diouron. 1999, XXV n. 29 y 136 niegan que se trate del mismo individuo. Ha de considerarse que todos los Escápulas que aparecen citados con relación a los hechos acontecidos en la zona meridional peninsular en la década de los años cuarenta han de ser una misma persona, seguramente de origen hispano, de alta posición social, como muestran las citas y sus acciones, que debió ser un acérrimo partidario de la causa pompeyana. Los diferentes nombres que recibe de los diferentes escritores clásicos quizás derivase de la mala conservación de su nombre en la transmisión de los manuscritos, o incluso venga ya de la redacción original de las obras. Seria excesivamente casual que con los pocos nombres conservados hubiera tanta coincidencia. 
neciente al orden ecuestre y muy posiblemente originario de Corduba, puesto que es en este lugar donde se suicidó y en donde estaba su familia ${ }^{64}$, y cuya riqueza provendría de las explotaciones mineras ${ }^{65}$.

No tiene nada que extrañar que uno de los conjurados contra Casio Longino participe posteriormente al lado de Cneo Pompeyo hijo. Esto se puede comprobar con el caso de $L$. Munatius Flaccus ${ }^{66}$, participó activamente en la conjura contra Casio Longino, ya que mató a un lictor y luego hirió a Casio Longino (BAlex. 52, 3). Logró, no obstante, salvar la vida probablemente mediante rescate, como otros miembros de la conspiración (BAlex. 54, 4-5. Val. Max. 9, 4, 2) ${ }^{67}$, ya que vuelve a aparecer dos años más tarde. Participó en la campaña del año 45 a.C. en el bando pompeyano, apoderándose de la ciudad de Ategua y masacrando a sus habitantes procesarianos; obligado a rendirse, por falta de recursos, obtiene de César la promesa de perdonarle la vida, entregando previamente la ciudad (BHisp. 19, 4. Dio Cass. 43, 33, 4. Front. Strat. 3, 14, 1).

\section{HISPANIA, TIERRA DE REFUGIO}

Dión Casio dice que Cneo Pompeyo hijo, como se acostumbra a realizar en condiciones turbulentas, para atraerse a la gente, comenzó a con-

64 Gonzalez Roman y Marin diaz. 1981-1985, 31; 1994, 246. Knapp. 1983, 25. Rodriguez NEILA, 1988, 248 y 275. CABALLOS RufINo, 1989, 266 considera al menos que es hispano. NiCOLET, 1966, 780 por el contrario, considera tanto a Escápula como a Aponio ricos romanos que se asentaron en la Peninsula, sobre la base, en el caso del primero, que poseia unos jardines en Roma (Cic. Att. 12, 38, 4; 12, 40,4), pero también se puede argüir en el mismo sentido de que se tratara de otro personaje diferente al presente Escápula es mencionado después de la derrota pompeyana en Munda: huye a Corduba junto a su familia y sus libertos, mandando elevar una pira, y luego una espléndida cena, y vestido con sus mejores arreos, distribuyó allí su dinero y alhajas entre su familia (BHisp. 33, 3). Luego cenó temprano, se ungió de una mezcla de resina y esencia de nardos; finalmente llamó a un esclavo y a un liberto que habia sido su concubino, ordenando al primero que le degollase y al segundo a que encendiese la pira (BHisp, 33, 4), en donde su cuerpo debió ser arrojado. Este Escápula es mencionado como general de Cneo Pompeyo hijo por Apiano, quien señala que encendió una pira y se arrojó a ella (App. BCiv. 2, 105), siendo asi diferente el relato entre el Bellum Hispaniense y Apiano en la forma, pero no en el fondo, como se puede apreciar. Como dice Harmand, 1970, 198-199 la muerte de Escápula es digna de Sardanapalo, que es un vivo ejemplo de la civilización helenística de la Bética tardorrepu bi ¡cana, pero a la vez también semi-bárbara. CASTILLO, 1982, 469 considera que Escápula pudo ser antepasado de los Anni Veri posteriores, es decir, de los antepasados del emperador, Marco Aurelio, puesto que esta autora recuerda que Annius Scapula, maximae dignitatis et gratiae provincialis horno (BAlex. 55, 2), lo que demuestra su alta posición social, aunque no signifique automáticamente su pertenencia al ordo equester.

6.5 ROdRIGUEZ NEILA, 1988, 248.

66 CASTillo, 1965, 133. GonzAlez ROMÁN, 1981, 200; 1986-1987, 72. GONZALEZ Román y MARIN DíAZ, 1981-1985, 30. GARCIA Y BELLIDO, 1985, 81-85, dan Corduba como patria de! personaje. Quizás 
ceder todos los favores posibles, tanto de palabra como de obra, especialmente después de la deserción de algunos Alóbroges que el rey Juba 1 de Numidia había apresado en la campaña contra Curión y se los había cedido (Dio Cass. 43, 30,3). Como consecuencia de su actuación, no sólo fue aumentando la devoción de sus hombres, sino que un gran número de adversarios, especialmente los que habían servido a las órdenes de Afranio, pasaron a su campo (Dio Cass. 43, 30, 4).

Obsérvese que Dión Casio menciona a Afranio y no a Varrón, es decir, que no se trata de las legiones II y Vernacula, sino de soldados que habian servido en la Citerior. Posiblemente se trate de veteranos pompeyanos del ejército vencido por César en llerda, que fueron licenciados, unos diez mil, y que al volver los hijos de Pompeyo a la Península se sintiesen obligados hacia ellos ${ }^{68}$. No en vano el Bellum Hispaniense, al describir las fuerzas de Cneo Pompeyo en la campaña de Munda, señala que, a parte de las cuatro legiones que tenian un valor militar, el resto estaba formado por auxiliares y desertores (BHisp. 7,5 ). No tiene nada de especial: Sexto Pompeyo no tuvo ninguna dificultad en volver a reunir una fuerza considerable después de Munda, formada a partir de soldados de su padre y de su hermano (App. BCiv. 4, 83) ${ }^{69}$.

Hispania se convirtió gracias a Cneo Pompeyo hijo en el refugio de los opositores a César (App. BCiv. 2, 103. BHisp. 1, 1. Val. Max. 3, 2, 13) ${ }^{70}$, papel que ya habia jugado anteriormente al comenzar las hostilidades entre Pompeyo Magno y César. El mismo Cicerón pensó en venir el año 49 a.C. (Cic. Att. $7,17,1 ; 7,18,2)^{71}$. Así, tras la derrota en Thapsus de

fuese de itafica, como otros miembros de la conspiración (BAlex. 52, 4).- De su situación social, GonzÁlez Roman, 1986-1987, 72. Gonzalez Roman y Marin Diaz, 1994, 287. consideran que hay que realizar la misma valoración que al resto de conjurados de los que se tiene datos explícitos.

67 Valerio Máximo lo califica como Pompeianis nominis acnor quam probabilior defensor.

68 ROLDAN, 1972, 113. SCHULTEN, 1940, 98 señala que en la desbandada republicana después de Thapsus, se capturó en una nave a $P$. Ligario, oficial de Afranio, a quien César habia dejado en libertad en Hispania junto con los demás (BAfr. 64, 1), es decir, perdonado por César en llerda (Caes. BCiv. 1, 87, 4), pero que había decidido ingresar de nuevo en las filas pompeyanas como tantos otros

69 Veleyo menciona que a Cneo Pompeyo hijo acudieron gentes de todas las partes del mundo que seguian al nombre paterno (Vell.. Pat. 2, 55, 2).

70 BLAZQUEZ, 1975, 29 considera que la llegada de refugiados politicos estaba igualmente motivada por las grandes riquezas existentes en Hispania, que permitian rehacer sus fortunas e incluso crear ejércitos

71 Es interesante la historia de C. Subernio Caleno, amigo de Cicerón. Antes del comienzo de la guerra civil (49 a.C.) había ido a Hispania, o con M. Terencio Varrón, con el fin de estar en una provincia donde, vencido Afranio, no habria de haber, a su juicio, más contienda, y alli tropezó con los mismos males que con tanto cuidado había querido evitar. Le sorprendió esta guerra repentina, provocada por Escápula y tan aumentada por Cneo Pompeyo hijo, que ya por ningún procedimiento puede ahora librarse de su desgracia (Cic. Fam. 9, 13, 1). 
las fuerzas senatoriales, muchos huyeron de África con destino a Híspania: los más conocidos son Sexto Pompeyo (cos. desig. 43 a.C.), P: Attio Varo (pr. 55 a.C.?) y T. Labieno (pr. c. 59 a. C.) ${ }^{72}$, junto con la flota (Dio Cass. 43, 30, 4).

Pero no siempre los que intentaban buscar refugio tuvieron la suerte de llegar. Entre otros muchos, Metelo Escipión y L. Manlio Torcuato (pr. 49 a.C.) embarcaron con rumbo a la Península Ibérica, pero un temporal los lanzó a la costa a la altura de Hippo Regius, donde fueron batidos por la escuadra de P. Sittio Nucerino, encontrando allí la muerte (App. BCiv. 2, 100. BAlex. 96, 1-2. Flor. 2, 13, 68. Liv. Per. 114, 5-6. Oros. 6, 16, 4-5. Sen. Lucil. 24, 9-10. Val. Max. 3, 2, 13). También el yerno de Pompeyo Magno, Fausto Comelio Sila (q. 54 a.C.), y L. Afranio, fueron capturados - y posteriormente ejecutados - al intentar llegar a Hispania (BAfr. 95, 1).

La escuadra que constituirá Cneo Pompeyo hijo no sólo contaría con las naves con las que habia llegado a Hispania $(B A f r .23,1)$ y con las supervivientes de la escuadra republicana de África (Dio Cass. 43, 30, 4), sino que también se construirían otras en los numerosos astilleros peninsulares, como ya antes en el año 49 a.C. había ordenado el legado pompeyano M. Terencio Varrón (Caes. BCiv. $2,18,1$ ) ${ }^{73}$ como porque Sexto Pompeyo disponía en el año 44 a.C. de una importante armada (App. BCiv. 4, 84).

La fuerza naval pompeyana así formada fue puesta al mando de $P$. Atio Varo, que ya habia dirigido la escuadra senatorial durante la campaña de África. Esta flota fue derrotada en el año 46 a.C. por la cesariana al mando de Didio frente a Carteia ${ }^{74}$ (Dio Cass. 43, 31, 3. Flor. 2, 13, 75-76). Es precisamente en esta localidad donde, durante la campaña de Munda, la escuadra pompeyana estuvo anclada (App. BC 2, 105. BHisp. 32, 6. Dio Cass. 43, 40, 1. Str. 3, 2, 2).

\footnotetext{
7. Apiano (App. BCiv. 2, 87) dice que Pompeyo, con Labieno y Escápula, cada uno con sus tropas, se dirigieron a Hispania, 10 que no es cierto, a raiz de los acontecimientos narrados por Dión Casio. Evidentemente. Escápula ya estaba en Hispania antes que Cneo Pompeyo hijo, mientras que Labieno llegó a la Peninsula después de la batalla de Thapsus. Sea como fuere, la mención de estos dos personajes muestra su importancia dentro del esquema organizativo militar pompeyano.

Varrón ordena la construcción de naves de guerra en Gades e Hispalis.

74 ROLDAN GOMEZ ET ALI/, 1998, 39 y 193 señala que esta importante población fue muy adicta a los pompeyanos, CHAVES TRISTAN, 1979, 100 considera que la emisión n. 22 de Carteia fue realizada en el año 45 a.C. por miembros del partido pompeyano, antes de la batalla de Munda.
} 


\section{PREPARATIVOS PARA LA RESISTENCIA}

Cneo Pompeyo hijo, para reclutar su ejército, apelaba a la fides de cada ciudad (BHisp. 1, 1), por lo que, según el Bellum Hispaniense, en parte con ruegos, en parte por la fuerza, obtuvo una fuerza considerable, con la que se puso a "devastar" la provincia de la Hispania Ulterior (BHisp. 1, 2), de tal forma que se adueño de ella mientras César se encontraba repartiendo mercedes en Italia (BHisp. 1, 1). Más correcto, Dión Casio señala que Cneo Pompeyo hijo, habiendo reunido un gran número de tropas, recorría el país sin miedo alguno (Dio Cass. $43,30,5$ ). Ocupaba algunas ciudades de buen grado y otras a la fuerza (BHisp. 1, 3. Dio Cass. 43, 30,5), de tal forma que parecía incluso que iba a aventajar en poderío a su propio padre, Pompeyo Magno (Dio Cass. 43, 30, 5), ya que cuanto más "forzaba" a la provincia, tanto más aumentaban sus fuerzas (BHisp. 1, 4).

La parcialidad del Bellum Hispaniense ${ }^{75}$ una obra eminentemente antipompeyana, se puede detectar claramente en la siguiente cita: quibus in rebus nonnullae civitates sua sponte auxilia mittebant, item nonnulfae portas contra claudebant. Ex quibus si qua oppida vi ceperat, cum aliquis ex ea civitate optime de Cn. Pompeio meritus civis esset, propter pecuniae magnitudinem aliqua ei inferebatur causa, ut eo de medio sublato ex eius pecunia latronum largitio fieret (BHisp. 1, 3-4) ${ }^{76}$.

Muchas veces esta frase ha sido mal interpretada, puesto que únicamente se ha considerado la segunda parte de la proposición, esto es, de que Cneo Pompeyo hijo al ocupar una ciudad (sin revelar si la comunidad militaba a favor o en contra de su causa), confiscaba los bienes de sus posibles partidarios, es decir, los que podían simpatizar con su causa. Si ello

LÓPEZ BARJA, 1995-1996, 178-179 indica muy bien que los lusitanos ejemplarizaban perfectamente la imagen de "bárbaro", como ilustra el Bellum Hispaniense (BHisp. 35-40). César, después de la batalla de Munda, reúne en Hispalis una asamblea de notables, en la que pronuncia un discurso en que, como López Barja indica, César considera a Cneo Pompeyo hijo una suerte de nuevo Sertorio: Priuatus ex fuga $\mathrm{Cn}$. Pompeius adulescens a uobis receptus fasces, imperium sibi arripuit, multis interfectis ciuibus auxilia contra populum Romanum comparauit (BHisp. 42, 6). Por tanto, para César, no se está frente a una guerra civil sino de una sublevación indígena provocada por un traidor a Roma, desprovisto de imperium $y$, por tanto, de legitimidad para dirigir tropas.

6) TOVAR y BLÁZQUEZ, 1975, 107 señalan que es un ejemplo típico de la propaganda hostil contra Cneo Pompeyo hijo, unánime en este sentido a excepción de Apiano. DıoURON, 1999, 44 señala que la palabra largitio, que designa las distribuciones de dinero destinadas a asegurar la fidelidad de las tropas, siempre es aplicada en el corpus cesariano, de forma peyorativa, a los jefes pompeyanos, a excepción de Casio Longino (BAlex. 49, 1). Igualmente, el término latronum hace referencia a las tropas constituidas de manera irregular, pero con el objetivo de presentar a las fuerzas pompeyanas como una banda de ladrones. 
fue así, su conducta ha de calificarse como absolutamente inmoral, atentando a la relación de fides entre patrón y cliente, es decir, la impietas ${ }^{77}$. Pero estas acciones pudieran deberse a que, si estos partidarios o clientes de Pompeyo Magno se encontraban en ciudades que se habian declarado contra su hijo mayor, éste podía considerar que habian traicionado precisamente su fides con él, heredero de su padre.

En realidad, puede que la frase del Bellum Hispaniense esté fuera de contexto. Muy posiblemente sea cierto que Cneo Pompeyo hijo castigase a algunos miembros de la oligarquía bética (los únicos que, evidentemente, podian detentar una fortuna: aristócratas, grandes mercaderes, etc.) que habían recibido favores de su padre, pero por haber apoyado a sus enemigos en vez de auxiliarle a él, versión notablemente diferente de la que ofrece el anónimo autor del Bellum Hispaniense, pero quizás más cercana a la realidad.

Ante el crecimiento del movimiento liderado por Cneo Pompeyo hijo, no es raro que las ciudades hostiles a éste enviaban sin cesar mensajeros a Italía pidiendo socorros (BHisp. 1, 5), como Corduba (BHisp. 2, 1). Ya se ha observado que no existía unanimidad en las diferentes comunidades en cuanto a apoyar u oponerse a Cneo Pompeyo hijo. Pero esta misma falta de unanimidad se puede encontrar dentro de las mismas ciudades, como en el propio cuartel general de los pompeyanos en esta campaña, Corduba, cuya guarnición mandaba Sexto Pompeyo (BHisp. 3, 1), como lo prueba la existencia en ella de caesarini y de pompeiani (BHisp. 34,1$)$. Igualmente, esta situación se puede constatar en otras poblaciones, como Hispalis (BHisp. 35, 1-4. Dio Cass. 43, 39, 2), Bursavo (BHisp. 22, 6), Carteia (BHisp. 37, 1-2), etc. ${ }^{78}$.

Aunque habia ciudades que apostaban decididamente por un partido en concreto. El ejemplo más claro es el de la ciudad de Ulia que, según Dión Casio, era la única ciudad que en la Ulterior se resistía a Cneo Pompeyo hijo (BHisp. 3, 1. Dio Cass. 43, 31, 4), fruto de la actitud filocesariana de sus habitantes, que ya antes habían exteriorizado durante la revuelta contra Casio Longino (BAlex. 61, 2-3) ${ }^{79}$. La fidelidad a César parece proceder de la década de los años sesenta, momento en que éste fue gobernador de la Ulterior ${ }^{80}$.

PASCUCCI, 1965, 124

78 Consúltese: J. MARTinez MERA, "Las ciudades Hispanas ante la Guerra Civil», ETF(Hist) 11 (1998), 307-333.

i9 Gonzalez Roman y Marin Diaz, 1981-1985, 20.

80 CORTIJO CEREzo, 1986-1989, 139. El hallazgo de un epigrafe en Ulia fechado en el año 49 a.C. dedicado a este personaje (AE $1986369=$ HEp 1 291) muestra la relación constante de esta ciudad con el entorno cesariano. 
A pesar de lo que comúnmente se cree, las acciones de Pompeyo Magno no se limitarían únicamente a la Bética, sino también a la provincia Citerior. No sólo se puede aludir al caso de Carthago Nova, en el mediodía peninsular, sino que la existencia de alguna noticia aislada que parece confirmarlo.

Durante la campaña de Munda, Arguecio, prefecto ${ }^{81}$ de César, llegó al campamento de César en Ategua con cinco banderas (signa) de Saguntum (BHisp. 10,1). Si bien se ha dicho que pudiera ser la bética Saguntia (Baños de Gigonza, prov. Cádiz) (Plin. NH 3, 15. Ptol. 2, 4, 10) ${ }^{12}$, parece mejor identificarla con la famosa ciudad del Levante hispánico del mismo nombre, que sería partidaria de Cneo Pompeyo hijo ${ }^{83}$. Beltrán Lloris pone en relación este suceso con la concesión de ciudadanía romana a los Fabii saguntinos (Cic. Balb. 51) por parte de Pompeyo Magno, lo que ocasionaría una relación de clientela ${ }^{84}$, cuyos frutos podría observarse en esta actuación.

Más interesante todavía es la noticia transmitida por Dión Casio, por la cual temeroso Cneo Pompeyo hijo de la noticia de la próxima llegada de César, no se veía capaz de "mantener toda Hispania", no esperó a ser derrotado y se replegó a la Bética (Dio Cass. 43, 31, 2) ${ }^{85}$. Evidentemente, ello significa que su domino superaba la citada región, pero es muy difícil evaluar hasta donde pudo alcanzar. La retirada de Cneo Pompeyo hijo puede observarse en el hecho de que los legados de César esperaron a éste en Obulco (BHisp. 2, 2. Dio Cass. 43, 31, 1. Str. 3, 4, 9), en la ruta a Corduba y Gades, cuya única explicación debe ser de tipo estratégico por parte de los pompeyanos.

Apiano menciona que el ejército de Cneo Pompeyo hijo estaba compuesto por los restos de los que lucharon en Pharsalus y África, junto a Iberos, Celtíberos y un gran número de esclavos emancipados (App.

81 BROUGHTON, 1952, 313. BALIL, 1963, 494. GONZÁLEZ ROMÁN, 1986-1987, 67 lo identifican con Clodio Arquecio, mencionado en BHisp. 23, 8, aunque no lo admiten PASCUCCI, 1965, 207. González Román y MARIN Diaz, 1981-1985, 29. CASTRO, 1992, 87 n. 37. Diouron, 1999, 75 y 100.

82 PASCuCCI, 1965, 207. CASTRO, 1992, 87 n. 38. Diouron, 1999, 76. Para ello, se arguye que Arguecio habria efectuado en gran parte su trayecto por mar, desembarcando en Gades o en Baesippo. Pero, más bien, al no indicarse nada en el Bellum Hispaniense, habría seguido la ruta terrestre tradicional de la via Heraclea.

83 SChULten, 1940, 286. BALIL, 1965, 353 n. 91. TOVAR, 1989, 286. BELtran LlORIS, 1982, 6667 n. 8. SOlANA SAINZ, 1989,89 consideran que la promoción jurídica de esta ciudad, federada en el año 56 a.C. (Cic. Balb. 23), municipio, debería ser posterior a la guerra civil

84 BELTRAN LLORIS, 1980,$385 ; 1982,66-67$ n. 8.

85. Cneo Pompeyo hijo habia distribuido por todas partes correos para que le informaran de la llegada de César (BHisp. 2, l). 
BCiv. 2,$87 ; 2,103)^{86}$. Puede suponerse que, al menos, la influencia pompeyana podía alcanzar la Ceitiberia, donde Pompeyo Magno habia concedido grandes beneficios a las comunidades que le habían apoyado en la guerra sertoriana (Caes. BCiv. 1, 61, 3) ${ }^{87}$. No en vano Pompeyo Magno había concedido importantes beneficios a toda Hispania, y era reconocida la gran clientela que disponia en la provincia de la Citerior, motivo por el que César quería someter completamente la Península Ibérica (Caes. BCiv. 2, 18,7), y que fue lo que precisamente atrajo a Cneo Pompeyo hijo (BAfr. 22, 4).

En relación con los preparativos de Cneo Pompeyo hijo para resistir a César, en diversos lugares de Andalucía se han encontrado gran número de ladrillos a nombre de $M$. Petrucidius $M$. f, leg(atus) pro pr(aetore) ${ }^{88}$, lo que se ha interpretado que este personaje impulsó una actividad edilicia con ánimos de fortificar diversos lugares de la Bética durante los años 4645 a.C., a nombre de Cneo Pompeyo hijo, con vistas al futuro enfrentamiento con César ${ }^{89}$. Esto estaría avalado por el hecho de que este personaje se considera originario del Piceno ${ }^{90}$, territorio donde Pompeyo Magno poseía grandes clientelas.

González sostiene que M. Petrucidio fue leg(atus) pro pr(aetore) en tiempos de Augusto, a finales del s. I a.C. (15/14 a.C.), que estaría encargado de reparar los daños ocasionados por la guerra civil en las ciudades más importantes (con estatuto privilegiado), como lo demuestra que los

86 No es de extrañar que en las filas pompeyanas hubiera esclavos, puesto que la aristocracia romana estaba acostumbrada a utilizar como soldados a sus clientes, libertos y esclavos. Consúltese: H. KÜLNE, "Zur Teilnahme von Sklaven und Freigelassenen au den Bürgerkriegen der Freien im 1. Jahrhundert v.u.Z. in Rom", StudClas 4 (1962), 189-209. N. RoulAND, Les esclaves romains en temps de guerre, Bruxelles, 1977.

87 BlÁzoUez, 1971, 46; 1975, 83. ROLDAN, 1972, 105. SALINAS dE Frías, 1983, 29; 1995, 109. SOLANA Y MONTENEGRO, 1986, 139.

88 Las inscripciones y localidades en la que se menciona la presencia de este personaje son las siguientes:

- Carteia (AE $1982546=\left.\mathrm{CIL}\right|^{2} 2298 \mathrm{a}=\mathrm{CIL}$ II 4967, 1a = HEp $2266=$ IRCád. 89): M. PETRUCIDILIS M. F. / LEG. PRO PR. M. LICl.

- Hasta Regia (CIL l² 2298a = CIL $\|$ 4967, 1a = IRCád. 33): M. PETRUCIDIUS M. F. / LEG. PRO PR. M- LICI.

- llipa (CIL I² 2298a = CIL \|l 4967, 1a): M. PETRUCIDIUS M. F. / LEG. PRO PR. M. LICI.

- Siarum (La Cañada) (AE $1990531=$ HEp 3 357): M. PETRUCIDIUS M. F. / LEG. PRO PR. // CN. TARQ.

- Itafica (quizás en realidad Urso) (ClL I² 2298b): [M. PETR]UCIDIUS M. F. / [LEG. PR]O PR. ALEX. ST.

89 Dessau, 1904, 560. Broughton, 1952, 519; 1985, 156. Balil, 1963, 493. AlFölDY, 1969, 174 y 180. Gasperini y Paci, 1982, 240. Lacort Navarro, Portillo y Strlow, 1986, 73. CabaLLOS RUFINO, 1994, 151. DIOURON, 1999, 133.

90 Gasperini y PaCi, 1982, 240. Caballos Rufino, 1994, 151. 
ladrillos se han encontrado en casas particulares y no en obras de fortificación, y a su vez embellecerlas con nuevos edificios civiles y religiosos ${ }^{91}$.

\section{EL EJÉRCITO DE CNEO POMPEYO HIJO}

El ejército principal, a las órdenes de Cneo Pompeyo hijo, disponía durante la campaña de Munda de trece legiones, cuyos componentes son descritos por el Bellum Hispaniense (BHisp. 7, 4-5; 30, 1; 31, 10) ${ }^{92}$. Junto a ellas, hay que añadir una fuerza de seis mil hombres de caballería con armadura ligera ${ }^{93}$ y otros tantos de tropas auxiliares ${ }^{94}$ - de infantería(BHisp 30, 1), es decir, 12.000 hombres ${ }^{95}$. Todo este conjunto ofrece un total de 70.000 soldados ${ }^{96}$.

91 GONZÁlez, 1989, 522-523. FerReIro, 1983, 95 lo considera de poco antes del año 27 a.C., con la misma finalidad. Los otros personajes que aparecen junto a $M$. Petrucidius: $M$. Lici(nius), Alexander y $\mathrm{Cn}$. Tar(quinius) serian los tegularii o más probablemente los conductores operarum de éste: el primero en Hasta Regia y Carteia, el segundo en Italica y el tercero en Siarum.

92 Aquilas et signa habuit XIII legionum; sed ex quibus aliquid firmamenti se existimabat habere duae fuerunt, Vemacula et Secunda, quae a Trebonio transfugerant, una tacto ex colonis qui fuerunt in his regionibus, quarta fuit Afraniana ex Africa, quam secum adduxerat; refiquae ex fúgitivis auxiliaribusque consistebant. Nam de levi armatura et equitatu longe et virtute et numero nostri erant superiores (BHisp 7, 4-5), PASCUCCI, 1965, 149 señala que quizás las once legiones que menciona Cicerón (Cic. Fam. 6, 18, 2) y las diez que atribuye Obsecuente (Obs. 66) pueden referirse a un momento anterior al conflicto que desembocaria en la batalla de Munda. Pudiera ser también que estas cifras equivaliesen a legiones completas, que equivaldrian a las trece del Bellum Hispaniense.

93 ROLDÁ, 1972, 104; 1974a, 175 considera que también se puede tratar de seis mil hombres entre caballeria e infantería ligera.

94 Indudablemente, debieron de existir otras unidades de auxiliares no contabilizadas en el ejército principal, y que son de difícil conocimiento. Como ejqmplo, hay que citar la derrota de cinco banderas (signa) de Saguntum (BHisp. 10,1) por el cesariano Ciodio Arquecio. Igualmente, hay que destacar la presencia de elementos auxiliares lusitanos, quienes no son mencionados por Apiano (App. BCiv. 2, 87; 2, 103). Después de la batalla de Munda, los Lusitanos siguieron acompañando a Cneo Pompeyo hijo, tomando parte muy poco después, por ejemplo, en la captura y defensa de Hispalis (BHisp. 36, 1. Oros. 6, 16, 9. Val. Max. 9, 2, 4). Son éstos los que casi exclusivamente mantendrán la resistencia contra César después de la derrota pompeyana en Munda, lo que demuestra que no habían sido obligados a combatir por la obligación impuesta de proporcionar contingentes a la fuerza o mediante el mercenariado (lo que igualmente debió utilizarse). Pero más que pensar en la gran devoción por parte de los indígenas de la personalidad de Pompeyo Magno y su enorme prestigio como gran patrón de Hispania, la actuación de los Lusitanos a favor de los pompeyanos parece deberse ante todo a las campañas que hicieron contra ellos tanto César en el año 61 a.C. (Dio Cass. 37, 52-53. Liv. Per. 103, 5. Plut. Caes. 12, 1) como Casio Longino en el año 48 a.C. (BAlex. 48, 2).

95. SANTOS YANGUAS, 1980, 702.

96 SChulten, 1940, 137. MONtenegro, 1982, 161. Del Bellum Hispaniense (BHisp, 30, 1). Schulten extrae la cifra de 70.000 hombres del ejército pompeyano en Munda, al considerar que cada "águila" (evidentemente, una legión), debía estar formada de unos 4.000 hombres (siendo generalmente una legión completa de 6.000 hombres) que, por 13 legiones, da la cifra de unos 50.000 
El Bellum Hispaniense señala que las únicas unidades útiles desde un punto de vista militar eran las dos legiones que habían desertado de Trebonio, las varronianas II y Vernacula, una formada con colonos de la provincia y una cuarta llegada de África que habia servido bajo Afranio $(B \text { Hisp } 7,4)^{97}$. Pero, hay que tener en cuenta que las otras nueve legiones estaban constituidas por fugitivos y auxiliares (BHisp 7,5$)$ que, a pesar de la exageración de la fuente ${ }^{98}$, procesariana, tiene grandes visos de verosimilitud. De hecho, los fugitivos citados por el Bellum Hispaniense deben ser elementos senatoriales supervivientes de las campañas de Pharsalus y África (App. BCiv. 2, 103) ${ }^{99}$, así como desertores del bando cesariano (sin contar a las dos legiones varronianas, que pasaron completas al servicio de Cneo Pompeyo hijo), especialmente los que habian servido anteriormente bajo Afranio (Dio Cass. 43, 30, 4), como ya se ha señalado. Que Apiano indique que las fuerzas de Cneo Pompeyo hijo llevasen cuatro años ejercitándose (App. BCiv. 2,103) indica que incluia tropas que llevaban en campaña desde el año 49 a.C.

La rebelión de las legiones varronianas contra Casio Longino y su posterior participación a favor de la causa pompeyana, representada por los hijos de Pompeyo Magno, les había llevado a que no pudieran tener la esperanza

\footnotetext{
legionarios, más 6.000 más de caballería e infantería ligera y ¡12.000! auxiliares, lo que daria un total redondeado de 70.000 hombres. La cita latina en cuestión no permite defender la tesis de este investigador, puesto que la fuente en cuestión señala que debia de haber el mismo número de caballería e infantería ligera (o mejor, de caballería ligera) que de tropas auxiliares, por tanto, 12.000 hombres en total, más las tropas legionarias, aunque debe considerarse que la cifra total de Schulten es correcta, puesto que las legiones debian de estar más completas, En referencia a la misma cita, se ha de tener en cuenta que no está nada claro si el autor queria decir que habia seis mil hombres de caballeria y de infantería ligera, más un mismo contingente aproximadamente de tropas auxiliares (de infanteria pesada, es decir, asimilable a la infanteria romana), o que habia seis mil hombres de caballería armados con armadura ligera y otros tantos auxiliares, éstos de infanteria, que quizás sea la solución más correcta, puesto que al enumerarse sus fuerzas, se dice que nostra praesidia $\angle X X X$ cohortibus, octo milibus equitum (BHisp. 30,1), es decir, que se menciona por un lado las fuerzas de infanteria y por otro las de caballeria. BRUNT, 1971, 474 considera que las tropas pompeyanas en Munda estaban únicamente compuestas por 45.000 hombres, ya que opina que participarian en la batalla tan sólo las once legiones, las citadas por Cicerón, como a que se aludan en las fuentes otras unidades militares pompeyanas en Corduba que debe suponer desgajadas del ejército principal. Más bien, hay que considerar la cifra anterior, basada en el Bellum Hispaniense, que describe las unidades participantes en el conficto; las tropas pompeyanas ubicadas en Corduba más bien hay que considerarlas una fuerza independiente del ejército principal. DIOURON, 1999, XLI y 123 supone unos efectivos del ejército pompeyano entre 50.000 y 60.000 soldados.

97 GABBA, 1970, 140. DiouRoN, 1999, XXXIX señalan correctamente, contra GSELL, 1928, 29 y 45 , que esta legión había servido con Afranio en África, y no de tropas que habian servido anteriormente en Hispania con Afranio y Petreyo.

98 ROLdÁN, 1974, 175. GONZÁleZ ROMÁN, 1978, 130.

99 De aqui que Veleyo diga que a Cneo Pompeyo hijo acudieron gentes de todas partes del mundo (Vell. Pat. 2, 55, 2).
} 
de ningún perdón, al igual que las tropas que había servido en Hispania bajo Afranio (Dio Cass. 43, 36, 3). Esta situación provocó que la batalla de Munda fuese una de las más sangrientas de la historia romana ${ }^{100}$.

A pesar de la existencia de un importante contingente de ciudadanos romanos en la región, es claramente sospechoso el reducido número de auxiliares hispánicos citados en el bando pompeyano por el Bellum Hispaniense, en comparación con la movilización del año 49 a.C. Por ello, parece forzoso admitir que estos "auxiliares" serían los Iberos, Celtíberos y esclavos emancipados que Apiano señala como integrantes de las fuerzas de Cneo Pompeyo hijo junto a los restos de los que lucharon en Pharsalus y África (App. BCiv. 2, 87; 2, 103), los cuales habrían sido admitidos en las legiones ${ }^{101}$. No en vano César, en su discurso ante la asamblea provincial en Hispalis después de la batalla de Munda, hecha en cara a los habitantes de la provincia de que hubiesen apoyado a Cneo Pompeyo hijo, quien auxilia contra populum Romanum comparauit (BHisp. 42, 6) ${ }^{102}$.

La situación de los pompeyanos era desesperada, pues constituían la única resistencia armada que en aquel momento se oponían a los designios de César. No es por ello raro de que aceptasen en sus fuerzas, en concreto en sus legiones, a cualquier elemento sin tener en cuenta términos jurídicos. Por ello, estas tropas no serían más que un conglomerado de antiguos soldados de Pompeyo Magno, tránsfugas del ejército cesariano, siervos escapados y veteranos auxiliares que por su larga relación podían participar en las legiones aunque no tuvieran el derecho de ciudadanía, que obtendrían en el mismo momento de su enrolamiento en las unidades legionarias ${ }^{103}$.

Muy posiblemente, la posibilidad de obtener dicho privilegio habría atraído a gran número de indígenas peregrinos a enrolarse en las filas pompeyanas. Esto explicaría tanto el alto número de unidades legionarias organizadas por los hijos de Pompeyo Magno en Hispania como los pocos auxiliares reclutados, cuyos mayores y mejores elementos estarían incluidos en los cuadros legionarios ${ }^{104}$. Igualmente, su irregular situación jurídica les llevaría a luchar denodadamente en la campaña de Munda.

\footnotetext{
100 HARMAND, 1970, 199.

101 GSELL, 1928, 39 considera que este mismo procedimiento habría sido utilizado por las fuerzas republicanas en África.

102 LÓPEZ BARJA, 1995-1996, 179 señala acertadamente que César presenta a Cn. Pompeyo hijo como si se tratase de un nuevo Sertorio, de manera que no se estaría frente a una guerra civil sino a una rebelión indigena.

103 ROLDÁN, 1972, 114.

104 HARMAND, 1970, 199.
} 
Aún quedaba otro ejército pompeyano en Corduba, al mando de Sexto Pompeyo, compuesto por varias legiones, las cuales estaban formadas por fugitivos y esclavos manumitidos (BHisp 34, 2), que, desde luego, no parece que estuviera compuesta por auténticos ciudadanos romanos, sino que hay que ver en ellos la misma problemática analizada ${ }^{105}$. Esta fuerza fue derrotada igualmente por César, perdiendo 22.000 hombres (BHisp 34, 5) ${ }^{106}$.

\section{ACUÑACIONES «OFICIALES»}

Es en su estancia en Hispania cuando tradicionalmente se han situado la emisión de dos denarios y de un as "oficiales" romanos a nombre de Cneo Pompeyo hijo (RRC 469-471) ${ }^{107}$, con el fin de poder pagar a sus tropas, siguiendo la tradición de su padre y su hermano en esta materia ${ }^{108}$, aunque debe destacarse el marcado carácter propagandístico de estas emisiones. El lugar de acuñación de estas piezas es muy dudoso, aunque es lógico considerar que debieron realizarse en la parte meridional de la Península, quizás en Cordubal ${ }^{109}$, o en Carthago Nova, pero no existe ningún dato que pueda situar con alguna certeza el lugar concreto ${ }^{110}$.

Las amonedaciones pompeyanas de Hispania reflejan la disposición de la gens Pompeia con respecto a la Península lbérica. Así, las acuñaciones de Pompeyo Magno (RRC 446-447) muestran la estrategia que pensaba seguir en el enfrentamiento contra César, mostrando la

105 ROLdaN, 1972, 114, Rodríguez NEILA, 1988, 275.

106 SCHULTEN, 1940, 139. ROLDÁN, 1972, 105 piensa que las fuerzas de Corduba serian los supervivientes de la batalla de Munda, lo que no parece lógiqo, puesto que César, después de su victoria, marchó inmediatamente hacia esta ciudad (BHisp 33, 1. Dio Cass. 43, 39, 1), con lo que de esta forma no permitiria la reorganización de las fuerzas huidas en la batalla anterior, aunque parte de los sobrevivientes de Munda lograron llegar a Corduba (BHisp. 33, 2). Hadas, 1930, 52 señala que parte de la dificultad creada se encuentra en que en el relato de Dión Casio, éste sufre una confusión en su descripción (Dio Cass. 43, 39, I), al tener en mente a las tropas que el Bellum Hispaniense habia descrito anteriormente. El relato del Bellum Hispaniense parece señalar que se trata de unidades diferentes a las que participaron en el combate de Munda: Erant hic (Corduba) legiones, quae ex perfugis conscriptae, parfim oppidanorum serui, qui erant a Pompeio Sexto manumissi (BHisp 34, 2).

107 Millán, 1965, 296-297. Campo, 1973, 63-64. Crawford, 1974, 479-481. Villaronga, 1979, 240. AMELA, 1990-1991, 184-185.

108 GIL FARRÉs, 1966, 233 señala que las emisiones pompeyanas peninsulares reflejan los distintos periodos de la guerra civil en Hispania.

109 GRANT, 1969, 22-24

110 AMELA, 1990-1991, 188. 
flota de Oriente y las legiones de Occidente ${ }^{111}$. Las de Cneo Pompeyo hijo representan la acogida $-\mathrm{y}$ ayuda - que recibió de las provincias hispanas (RRC 469-471) ${ }^{112}$, convirtiéndose la Península Ibérica en el único territorio que resistió al invencible César ${ }^{113}$. En cambio, las acuñaciones de Sexto Pompeyo son más reservadas (RRC 477-479), debido a las muertes de su padre y de su hermano, a quienes recuerda; $\sin$

111 Consúltese: L. AmEla ValVERDE, "Acuñaciones de denarios romano-republicanos de Pompeyo Magno en Hispania durante el año 49 a.C.», GN 134 (1999), 15-23.

${ }_{112}$ La descripción de las acuñaciones realizadas por Cneo Pompeyo hijo en la Peninsula es la siguiente:

1) RRC 469. CN. MAGNUS IMP. y M. POBLICI LEG. PROPR., denario.

- RRC 469/1a. Anv.: cabeza de Roma a dra., con casco corintio; antes M POBLICI LEG PRO hacia arriba, detrás $P R$ hacia abajo; línea de cuentas y puntos. Rev.: figura masculina con traje militar, quizás $\mathrm{C}$. Pompeyo hijo a la dra., sobre la proa de un barco, recibe una rama de palma de una figura femenina (la Ulterior o Hispania) a izq., armada con dos jabalinas y un escudo; a dra., CN MAGNVS IMP hacia arriba. Línea de puntos.

- RRC 46911 b. Anv.: igual. Rev.: igual, pero la proa de la nave más grande.

-- RRC 46911 c. Anv.: igual. Rev.: igual a la 1a, pero la rama de palma con raiz más larga.

- RRC 469/1d. Anv.: igual. Rev.: igual a la 1b, pero la rama de palma con raíz más larga.

- RRC 469/1e. Anv.: igual, pero antes MPOBLICI LEG hacia arriba, detrás PRO PR hacia abajo; linea de puntos. Rev.: igual.

Cuños de anverso: [42]. Cuños de reverso: [47].

2) RRC 470. CN. MAGNUS IMP, y M. MINAT. SABIN, PR(O)Q., denario.

- RRC 470/1a. Anv.: cabeza de Pompeyo Magno a dra., alrededor leyenda (diversas variantes: CN MAGNUS IMP, CN MAGN IMP, CN MAGNUS IM F, CN MAGN IMP F, CN MAGNUS IMP $B)$, línea de puntos. Rev.: figura masculina a dra., quizás Cneo Pompeyo hijo, desembarcando de la popa de un barco, y es saludado por una figura femenina a izq., quizás la Ulterior o Hispania, con una corona torreada, sobre un montón de armas, llevando en la mano izq. una lanza y con la mano dra. saludando a la figura masculina con traje militar que se ha descrito al principio; en exergo M MINAT SABIN, sobre la izq. $P R Q$ hacia arriba, línea de puntos.

- RRC 470/1b. Anv.: igual. Rev.: figura femenina situada a dra., con una corona torreada, levantando la mano dra. para saludar a la figura masculina con traje militar, la cual recibe un escudo de otra figura femenina de rodillas a izq., con corona torreada; en exergo M MINAT SABI, sobre la izq. $P R Q$ hacia arriba; línea de puntos.

- RRC 470/1c. Anv.: igual. Rev.: figura femenina a dra. con corona torreada, llevando un caduceo (simbolo de la felicitas) en la mano izq. y con la mano dra. ofrece una rama de palma a una figura masculina que está de cara, inclinado sobre una lanza con la mano dra.; a dra. otra figura femenina, andando hacia la izq., llevando una corona torreada, con un trofeo en la mano izq. y en la mano dra. una corona que ofrece a la figura masculina; en exergo M MINAT SABIN, sobre la izq. $P R Q$ hacia arriba; linea de puntos.

- RRC 470/1d. Anv.: igual. Rev.: Igual, pero sin rama de palma o lanza; figura femenina y soldado se estrechan las manos.

Cuños de anverso: 5 (2 recortados). Cuños de reverso: 8 .

3) RRC $471 C N$. MAG. IMP., as.

- RRC 47111. Anv.: cabeza laureada de Jano, encima 1. Rev.: proa a dra., encima $C N 113$ $M A G$, antes I., debajo IMP.

113 Consúltese: TH. V. Buttrey (Jr.): "The Denarii of Cn. Pompeius Jr. and M. Minatius Sabinus", ANSMUSN 9 (1960), 75-94. L. AMELA VALVERDE, "Acuñaciones de Cneo Pompeyo hijo en Hispania", Numisma (en prensa). 
duda, pretendía de este modo consolidar la simpatía y colaboración de sus partidarios ${ }^{114}$.

Los reversos de los dos denarios de Cneo Pompeyo hijo son una manifestación de sus movimientos en la Península lbérica y de su acogida triunfai por sus habitantes, en especial de los que guardaban recuerdo de su padre (Dio Cass. 43, 30, 1. Vel. Pat. 2, 55, 2). Las emisiones RRC 469 y 470/1a muestran el desembarco del hijo mayor de Pompeyo Magno en Hispania, siendo recibido por la personificación de este territorio, mientras que las RRC $470 / 1 \mathrm{~b}-1 \mathrm{~d}$ representan ambas provincias, Citerior y Ulterior, dando la bienvenida a Cneo Pompeyo hijo, señal de su identificación con la causa pompeyana. La figura masculina que representa a Cneo Pompeyo hijo (mucho mejor que considerarla un soldado que simbolice el ejército pompeyano) va en traje militar, mientras que las figuras femeninas (Hispania y sus divisiones administrativas) van armadas, posiblemente alegorías del apoyo militar a la causa pompeyana.

En cuanto a los anversos de los denarios, el perteneciente a la RRC 469 exhibe la figura de la diosa Roma, cuya ayuda era invocada por el partido pompeyano contra el "usurpador», César. Por su parte, la RRC 470 muestra la cabeza de Pompeyo Magno, representada según el modelo helenístico (con objeto de asemejarlo al monarca macedonio Alejandro Magno, debido a la conocida imitatio Alexandri que practicaba el padre de Cneo Pompeyo hijo), ejemplo de la piedad filial del hijo con su padre y de la reivindicación de su memoria, una característica de los hijos de Pompeyo Magno. La presencia de este último en las amonedaciones de sus hijos es sin duda un magnífico instrumento de propaganda para recordar la fides debida a su persona.

Sobre la alegoría de la moneda de bronce (RRC 471), la proa del reverso (que aparece igualmente en las acuñaciones de bronce hispánicas de Sexto Pompeyo, RRC 478-479) posiblemente aluda a la ya mencionada flota de Cneo Pompeyo hijo, aunque igualmente refleja un evidente tinte tradicionalista, al representar el motivo de los antiguos ases republicanos. En cuanto a la figura de Jano en el anverso, las acuñaciones de bronce de Sexto Pompeyo lo siguen representando, pero esta vez con los rasgos de su padre Pompeyo Magno (RRC 479), que no es más que una anticipación del concepto del divi filius de Augusto.

114 Consúltese: TH. V. Buttrey (Jr.): "The «Pietas" denarú of Sextus Pompey", NC 10 (1960), 53- 101. L. AmELA VALVERDE: "Las acuñaciones romanas de Sexto Pompeyo en Hispania", AEspA 73 (2000), 105-119. 


\section{LA CLIENTELA POMPEYANA}

La importancia de la clientela pompeyana (BAfr. 22, 4. Caes. BCiv. 2, 18, 7. Sall. Cat. 19, 5) ${ }^{115}$ y su lealtad ${ }^{116}$ permitió que la Península lbérica fuese durante los años 49-44 a.C. el gran bastión anticesariano, y no es nada exagerado decir que se ha considerado a ésta como la fortaleza tradicional de la gens Pompeia ${ }^{117}$, donde su nombre era conocido y respetado. En otras regiones del Mediterráneo, la victoria de César desbarataba y eliminaba al partido filopompeyano, no volviéndose a producir ningún nuevo levantamiento contra éste; sólo Hispania fue la excepción.

Esta clientela fue forjada por Cneo Pompeyo Magno ${ }^{118}$, durante su participación en la guerra sertoriana (82-72 a.C.), momento que aprovechó para extender su influencia en esta región del Occidente romano (Caes. BCiv. 1, 61, 3), como ya había hecho anteriormente en Sicilia, África y Galia Transalpina. La obtención de clientes se debía a la concesión de diversos beneficios que un determinado personaje realizaba durante el ejercicio de una magistratura, junto a la realización de actos importantes de propaganda como demostración de su valía para, de esta forma, granjearse la admiración y la gratitud de la población. En este campo, Pompeyo Magno fue un maestro, como manifiesta el gran poder que alcanzó dentro de la república romana.

115 Consúltese: L. AMELA VALVERDE: "El desarrollo de la clientela pompeyana en Hispania», SHHA 7 (1989), 105-117; “La clientela de Cneo Pompeyo Magno en Hispania», Historia y Vida 270 (1990), 90-97; La clientela de Cneo Pompeyo Magno en Hispania, Diss. Barcelona, 1999.

116 SChULTEN, 1940, 94 y 125. SANCHEZ-ALBORNOZ, 1949, 23. Rossi, 1953, 293. CARCOPINO, 1968, 458. Harmand, 1970, 183. Rodriguez Nella, 1988, 252. Montenegro, 1986, 203. Roddaz, 1988, 325. ALONSO-NÚNEZZ, 1999, 118.

117 TAYlor, 1949, 45. BlazQuez, 1975, 83. Solana y MONTENEgRo, 1986, 120-121. WelCH, 1995, 450.

118 También ha de tenerse en cuenta a su padre, Cn. Pompeyo Estrabón (cos. 89 a.C.) quien, mediante la concesión de la ciudadanía romana a un grupo de jinetes ibéricos, la turma Salluitana $\left(\mathrm{CIL} 1^{2}\right.$ 709. CIL VI 37045. ILLRP 515. ILS 8888) intentaba extender su influencia a Hispania. Consúltese: E. PAIS, "ll decreto di Gn. Pompeio Strabone sulla cittadinanza romana del cavalieri ispani», en Ricerche sulla storia e sul difitto romano. Dalle guerre puniche a Cesare Augusto. Indagini storiche-epigraphiche-giuridiche. Parte Prima (Roma, 1918), 169-226. M. GOMEZ MORENO: "Sobre los íberos: el Bronce de Ascoli", en Misceláneas. Historia-Arte-Arqueología (dispersa, emendata, addita, inedita). Primera serie: la Antigüedad (Madrid, 1949), 233-256. N. CRINITI, L'epigrafe di Ausculum di Gn. Pompeo Strabone, Milano, 1970; L'epigrafe di Ausculum di Gn. Pompeo Strabone. Supplemento, Milano, 1987. J. M. RoLdAN HERVAS, "La turma Salluitana. Caballería hispana al servicio de Roma", Historia 16110 (1985), 51-60; "El bronce de Ascoh en su contexto histórico", en Reunión sobre epigrafia hispánica de época romano-republicana. Actas 1986 (Zaragoza, 1986), 115-135; "Los reclutamientos romanos en el valle del Ebro, en época republicana", en Estudio en Homenaje al dr. Antonio Beltrán Martínez (Zaragoza, 1986), 761-779. L. AMELA VALVERDE: "La turma Salluitana y su relación con la clientela pompeyana», Veleia (en prensa). 
Los métodos que se utilizaron fueron varios, entre los cuales se han de citar: el patronazgo sobre colectividades públicas, establecimiento de soldados veteranos, concesiones de ciudadanía romana, realización de pactos de hospitium y amicitia, etc. ${ }^{119}$. Estos procedimientos afectaban a todas las capas sociales existentes en la Península lbérica, logrando que gran parte de sus habitantes se identificaran con la gens Pompeia ${ }^{120}$. El resultado fue que gran parte de Hispania apoyase sin reservas la causa pompeyana contra César, aunque no debe considerarse como la única causa de la resistencia de los hijos de Pompeyo, pero sí quizás la más importante.

En todo momento estaba presente el prestigio de Pompeyo Magno como gran patrón de Hispania y sus relaciones personales basadas en la fides con muchas comunidades y notables indígenas ${ }^{121}$. Mediante el método de acudir a la fides de las ciudades, Cneo Pompeyo hijo consiguió un importante número de tropas, con las que se dedicó a recorrer la provincia (BHisp. 1, 2). Sin duda alguna, esta opinión estaba fundamentada en los numerosos beneficios que había realizado Pompeyo Magno durante la guerra sertoriana y durante el segundo lustro de los años cincuenta ${ }^{122}$, que haria que la mayor parte de sus clientes como de sus partidarios le fueran fieles a su persona y a la de sus hijos.

La lealtad de los hispanos con Pompeyo Magno y sus hijos se puede observar por los distintos ejércitos que se levantaron en su defensa, a pesar de la derrota de llerda. Así, en el año 45 a.C. Cneo Pompeyo hijo disponía de un ejército de trece legiones (BHisp. 7, 4-5), mientras que Sexto Pompeyo a su vez tenía un número indeterminado de legiones, pero cuyo número pasaba de los 22.000 soldados (BHisp. 34, 2-5). Aunque todas estas tropas fueran igualmente derrotadas, Sexto Pompeyo no tuvo ninguna dificultad en volver a reunir una fuerza considerable, formada a partir de soldados de su padre y de su hermano (App. BCiv. 4, 83), llegando a poseer en un determinado momento al menos siete legiones (Cic. Att. 16, 4, 2).

En otros temas, se puede igualmente advertir la lealtad que se tenia a los pompeyanos como es, por ejemplo, la actitud mostrada por las antiguas legiones varronianas, la II y la Vernacula; la postura de Escápula; la

\footnotetext{
19 ROLDAN, 1978b, 145-146. MONTENEGRO, 1982, 147. SAlinas de Frías, 1986, 28. Solana y MONTENEGRo, 1986, 121-122. AMELA, 1989, 114.

120 HARMAND, 1970, 183

121 ROLDAN, 1972, 99 y 116.

122 Consúltese: J. M. Roldán Hervas, "Las provincias hispanas en la era de Pompeyo", en Historia de España Antigua II. Hispania Romana (Madrid, 1978), 141-153. L. AMELA VALVERDE: «Pompeyo Magno y el gobierno de Hispania en los años 55-50 a.C.", HAnt (en prensa).
} 
fidelidad de varias ciudades durante la campaña de Munda (Corduba, Munda, Urso), etc.

El testimonio de Floro es vital para conocer la causa de la fuerza e importancia del movimiento pompeyano antes de la batalla de Munda: plurimum quantum favoris partibus dabat fraternitas ducum et pro uno duos stare Pompeios (Flor. 2, 13, 74). Otros autores clásicos señalan que la resistencia estaba dirigida por los dos hijos de Pompeyo (Eutrop. 6, 24. Oros. 6, 16, 6. Plut. Caes. 56, 1. Vir. III. 78, 8. Suet. Caes. 56, 1. Zon. 10, 10).

Indudablemente, la presencia de Cneo Pompeyo hijo y Sexto Pompeyo en Hispania había de favorecer el renacimiento de su facción, como expresa Floro. Quizás por ello fue el hijo mayor de Pompeyo Magno, y no ni Afranio ni Petreyo, antiguos legados de éste, quien fue enviado a la Península lbérica a encabezar la resistencia contra César (App. BCiv. 2, 103. Dio Cass. 43, 28, 1. Liv. Per. 115, 5. Obs. 66. Vell. Pat. 2, 55, 2). No en vano el epítome de Livio y Veleyo establecen claramente que se trata de: Cn. Pompeius Magni filius (Liv. Per. 113, 3. Vell. Pat. 2, 55, 2), y obsecuente, al enumerar las fuerzas pompeyanas en Munda, señala que: Decem legionum aquilae Gnaeo, Cn. Pompeii filio (Obs. 66). Plutarco menciona que Hispania se pasa al hijo de Pompeyo (Plut. Cat. min. 59, 9). No parece haber duda de que el mando supremo de las fuerzas militares lo tenia Cneo Pompeyo hijo, mientras que su hermano Sexto Pompeyo se ocupaba de la guarnición de la ciudad de Corduba (BHisp. 3, 1), caput de la provincia de la Hispania Ulterior (BHisp. 3, 1), y cuartel general de los pompeyanos en esta campaña.

Los otros jefes pompeyanos no parecen tener mucha importancia, al menos desde un punto de vista político: P. Atio Varo y $T$. Labieno, quienes llegaron junto con Sexto Pompeyo huyendo de África con la flota (Dio Cass. $43,30,4){ }^{123}$. Varo es citado como comandante de la flota pompeyana (ya hizo este papel para la escuadra senatorial durante la campaña de África: BAfr. 44, 2; 62, 1) derrotada frente a Carteia (46 a.C.) (Dio Cass. $41,31,3$. Flor. 2, 13, 75) o como comandante de una serie de fortines (BHisp. 27, 2), mientras que Labieno es mencionado en el desarrollo de la batalla de Munda (Dio Cass. 41, 38, 2. Flor. 2, 13, 83) ${ }^{124}$.

Sin lugar a dudas, aqui se debió repetir una situación parecida a la de las fuerzas republicanas de África: el mando nominal estaba en manos de

\footnotetext{
Atio Varo.

123 Orosio (Oros. 6, 16, 6) cita como jefes a Cneo Pompeyo hijo, Sexto Pompeyo, Labieno y

124 La muerte de Varo y Labieno en Munda es citada por varios autores (App. BCiv. 2, 105. BHisp, 31, 9. Oros. 6, 16, 8. Vell. Pat. 2, 55, 4).
} 
Metelo Escipión, pero no parece haber duda de que el mando real de las operaciones lo ejercía Labieno, el lugarteniente por excelencia de César en las Galias. Un episodio del Bellum Hispaniense, la ejecución de ciudadanos de Ategua, había indignado a Cneo Pompeyo joven y a Labieno (BHisp. 18, 9), lo que parece indicar que se encontraban en un plano de igualdad. Labieno es quien dirige las tropas pompeyanas durante la batalla de Munda (Dio Cass. 43, 38, 2. Flor. 2, 13, 83), no Cneo Pompeyo hijo. No en vano Apiano lo señala como uno de los dirigentes de la tropas pompeyanas en Hispania, junto con Escápula y Cneo Pompeyo hijo (App. BCiv. 2, 87).

Escápula debió jugar también un importante papel, al menos desde el punto de vista político (el Bellum Hispaniense únicamente lo cita para dar cuenta de su muerte, BHisp. 33,3), como líder de los pompeyanos de la Ulterior. No debe olvidarse que Escápula y Aponio son los que promueven la sublevación de la Bética y expulsan a Trebonio (Dio Cass. 43, 29, 3).

En África, los hijos de Pompeyo Magno estaban en un segundo plano con respecto a los otros jefes republicanos. Allí se seguia rigurosamente el orden de precedencia del Cursus Honorum en la concesión de los puestos de mando, como se realizaba en el Senado, al más viejo estilo republicano ${ }^{125}$; lo que desde luego no sería del agrado de los dos hijos de Pompeyo ${ }^{126}$. En Hispania, como se puede observar, la situación fue diferente, ya que ambos hermanos detentaban el mando supremo del ejército, el mayor como comandante en jefe, y el segundo como responsable de la defensa de Corduba, la capital. Ello se explica tanto por la desaparición de la mayor parte de los líderes como consecuencia de la batalla de Thapsus (M. Porcio Catón, Q. Cecilio Metelo Pío Escipión Nasica, L. Afranio, M. Petreyo, Fausto Cornelio Sila, etc.) como porque los hijos de Pompeyo habían acudido a la Península Ibérica precisamente por la fuerza e importancia de las paternae clientelae (BAfr. 22, 5).

\footnotetext{
125 Después de la batalla de Pharsalus, en Corcyra, Catón de Útica había reunido un ejército y una flota considerable, pidió a Cicerón que tomara el mando según la ley delante de otros por su dignidad consular (Plut. Cato $\min .55,5$; Cic. 39, 1). Cicerón se negó, ya que no quería proseguir en la lucha, lo que ocasionó que Cneo Pompeyo hijo quisiera matarlo, lo que no sucedió por intervención de Catón (Plut. Cato min. 55, 6; Cic. 39, 2). Por ello, Metelo Escipión fue el comandante en jefe de las fuerzas senatoriales en África (App. BCiv. 2, 87. Dio Cass. 42, 57, 2-3. Liv. Per. 113 1. Plut Cato min. 57, 6-7. Vell. Pat. 2, 54, 3. Vir. III. 80), un error del que posteriormente se lamentó Catón por conducir mal la guerra (Cic. Cato min. 58, 10-11). De aquí que Cicerón considerase que Cneo Pompeyo hijo era poco inteligente y consideraba la crueldad como una virtud (Cic. Fam. 15, $19,4)$ y que Séneca (Sen. Suas. 1, 5) refiera que Cicerón temiera que sus burlas sobre éste las devolviese "con la espada". Como excelentemente señala CANFORA, 1999, 336, no es más que un retrato "silano" del hijo mayor de Pompeyo Magno.

126 Rossi, 1953, 293.
} 


\section{BIBLIOGRAFIA}

Alonso NúN̄ez, J. M. (1999): «La Turdetania de Estrabón». En Estrabón en lberia: Nuevas perspectivas de estudio (Málaga), $101-119$.

AmEla VALVerde, L. (1989): "El desarrollo de la clientela pompeyana en Hispania". SHHA 7 , 105-117.

AMELA VALVERDE, L. (1990-1991): «La amonedación pompeyana en Hispania. Su utilización como medio propagandístico y como reflejo de la clientela de la gens Pompeia». Faventia 12-13, 181-197.

Amela Valverde, L. (en prensa): "Acuñaciones de Cneo Pompeyo hijo en Hispania". Numisma.

Arévalo, A. y CAMPo, M. (1998): "Las emisiones romanas y sus imitaciones en Hispania durante la República". En Historia monetaria de Hispania antigua (Madrid), 318- 334.

Arias VILAS, F.; LE Roux, P. y TranoY, A. (1979): Inscriptions romaines de la province de Lugo. Paris.

BALIL, A. (1963): “Funcionarios y oficiales subalternos en la España romana durante la época republicana". Hispania 23, 483-494.

BALIL, A. (1965): «Riqueza y sociedad en la España romana (ss. III-। a.C.)». Hispania 25, 325366.

BELTRAN LloRIS, F. (1980): Epigrafía latina de Satuntum y su Territorium (cronologia, territorium, notas prosopográficas, cuestiones municipales). Valencia.

BELTRÁN LLORIS, F. y M. (1982): “Numismática hispanorromana de la Tarraconense». Numisma $162-164,8-98$.

Beltrán Martinez, A. (1949): Las monedas latinas de Cartagena. Murcia.

Beltrán Martinez, A. (1952): "Sobre las antiguas monedas latinas y especialmente de Carthago-Nova. Refutación de algunas teorias sustentadas por Mr. Michel Grant en su obra "From Imperium to Auctoritas" (Cambridge, 1946)". Numisma 2, 9-40.

BlazQuez MARTínez, J. M. (1971): “La Iberia de Estrabón». HAnt 1, 11-94.

BlÁzquez Martinez, J. M. (1975): Ciclos y temas de la Historia de España: la Romanización, II. La Sociedad y la Economía en la Hispania romana. Madrid.

Broughton, T. R. S. (1952): The Magistrates of the Roman Republic. Volume II. 99 B.C. 31 B. C. Atlanta.

Broughton, T. R. S. (1985): The Magistrates of the Roman Republic. Volume III. Supplement. New York.

Brunt, P. A. (1971): Italian Manpower (225 B. C. -A. D. 14). London.

Burnett, A.; AmAndRY, M. y RIPOLLÉs, P. P. (1992): Roman Provincial Coinage. Volume I. From the death of Caesar to the death of Vitellius (44 B.C.-A.D. 69). Part I: Introduction and Catalogue. London.

Caballos Rufino, A. (1989): "Los senadores de origen hispano durante la República Romana". En Estudios sobre Urso. Colonia lulia Genetiva (Sevilla), 233-279.

Caballos Rufino, A. (1994): «La revolución romana en la Provincia Bética (de las guerras civiles a la Paz de Augusto)". En Actas del /l Congreso de Historia de Andalucia 3, Historia Antigua (Córdoba), 149-157.

CAMPO, M. (1973): "Los denarios romano-republicanos acuñados en Hispania". ANum 3, 53-64.

Canfora, L. (1999): Gulio Cesare. I/ dittatore democratico. Bari.

Carcopino, J. (1968 $)$ : Jules César. Paris.

Castillo Garcia, C. (1965): Prosopographia Baetica. 2 vol. Pamplona.

Castillo Garcia, C. (1975): "Städte, und Personen der Baetica". ANRW \| 3, 601-654.

Castillo Garcia, C. (1982): "Los Senadores Béticos. Relaciones familiares y sociales". En Epigrafia e Ordine Senatorio II (Roma), 465-519.

CASTRO SÁnChEZ, J. (1992): La guerra de Hispania. Edición bilingüe de... Madrid.

Chaves Tristán, F. (1979): Las monedas Hispano-Romanas de Carteia. Barcelona.

Cortiuo Cerezo, M. L. (1986-1989): “El municipio de Ulia». HAnt 13, 33-52.

Crawford, M. H. (1974): Roman Republic Coinage, 2 vols. Cambridge.

DESSAU, H. (1904): "De tegulis quibusdam in Baetica repertis". Eph. Ep. 9, 560-564.

Diouron, N. (1999): Pseudo-César. Guerre d'Espagne. Texte établi et traduit par. Paris.

ÉTIENNE, R. (1997): Jules César Paris.

FERREIRO LOPEZ, M. (1983): “Inscripciones relativas a Asta Regia». Gades 11, 85-104.

Ferreiro López, M. (1993): "Los legados de César en España». En // Congreso Peninsular de História Antiga. Actas (Coimbra), 399-415. 
Garcia Garrido, M. y LaLANA, M. (1991-1993): "Algunos glandes de plomo con inscripciones latinas y púnicas halados en Hispania". ANum 21-23, 101-107.

GASPERINI, L. y PACI, G. (1982): “Italia: Regio V (Picenum)». En Epigrafia e Ordine Senatorio // (Roma), 201-244.

Gelzer, M. (1968): Caesar Politician and Statesman. Oxford.

GElzER, M. (1969): The Roman Nobility. Oxford.

GIL FARRES, O. (1966): La moneda hispánica en la edad antigua. Madrid.

Gonzalez Fernandez, J. (1989): «M. Petrvcidivs M. f legatvs pro pr". Athenaeum 67, 517-523.

González Román, C. (1978): "Guerra civil y conflictos sociales en la PHU en el 48-44 a.C.". En Actas I Congreso de Historia de Andalucia. Fuentes y metodologia. Andalucia en la antigüedad (Córdoba), 131-141.

GONZÁLEZ ROMAN, C. (1981): Imperialismo y romanización en la provincia Hispania Ulterior, Granada.

GonzÁlez Roman, C. (1986-1987): “La onomástica del "Corpus" Cesariano y la sociedad de la Hispania meridional". SHHA 4-5, 65-77.

Gonzalez Roman, C., y Marin Diaz, M. A. (1981-1985): “El Bellum Hispaniense y la romanización del sur de la Península». HAnt 11-12, 17-35.

Gonzalez Roman, C., y Marin Diaz, M. A. (1994): "Prosopografía de la Hispania Meridional en época repúblicana". En La Sociedad de la Bética. Contribuciones para su estudio (Granada), 241-318.

Gozalbes Cravioto, E. (1994): “La intervención de la Mauritania de Bogud en las guerras civiles romanas en la Provincia Hispania Ulterior». En Actas del II Congreso de Historia de Andalucia 3. Historia Antigua (Córdoba), 287-293.

Grant, M. (1969'): From Imperium to Auctoritas. A Historical Study of Aes Coinage in the Roman Empire 49 B.C.-A.D. 14. Cambridge.

GSELL, S. (1928): Historie ancienne de I'Afrique du Nord. Tome VIII. Jules César et l'Atrique. Fin des royaumes indigénes. Paris.

Hadas, M. (1930): Sextus Pompey. New York.

Hamblenne, P. (1973): "L'opinion romaine et les sentences "politiques" de Publilius Syrus". ANRW I, 3, 631-702.

HARMAND, J. (1970): “César et l'Espagne durant le second bellum civile». En Legio VIl Gemina (León), 181-203.

Hiliman, Th. P. (1992b): The Reputation of Cn. Pompeius Magnus among his contemporanes from 83 to 59 B.C. Diss. Ann Arbor.

HoRst, E. (1981): César. Paris.

KNAPP. R. C. (1983): Roman Cordoba. Berkeley.

Lacort Navarro, P. J.; Portillo, A., y Stylow, A. U. (1986): "Inscripciones latinas de Córdoba y su provincia". Faventia 8/1, 69-109.

LINTOTt, A. W. (1993): Imperium Romanorum. Polifics and Administration. London.

MAÑANES, T. (1981): El Bierzo prerromano y romano. León.

MILLAN, C. (1965): "Aspectos hispánicos de la familia Pompeia». En Congresso internazionale di Numismática, II. Atti 1961 (Roma), 293-298.

Montenegro Duoue, A. (1982): "La conquista de Hispania por Roma (218-19 a.C.)". En Historia de España dirigida por Menéndez Pidal. Tomo Il. España Romana (218 a. de J.C.414 de J.C.), Volumen. I. La conquista y la explotación económica (Madrid), 1-210.

Montenegro DuQue, A. (1986): “El régimen administrativo romano y la evolución de las organizaciones politicas indígenas". En Historia de España 3. España romana (Madrid), 161210.

NiCOLET, C. (1966): L'ordre équestre a l'époque républicaine (312-43 av. J. C.). Tome 1. Définifions juridiques et structures sociales. Paris.

Ooteghem, J. van (1954): Pompée le Grand, bátisseur d'empire. Bruxelles.

PAscuccl, G. (1965): Bellum Hispaniense. Introduzione, testo critico e commento a cura di... Firenze.

Perez Vilatela, L. (1988): “Pompeyo y los Pirineos». En Congreso Internacional Historia de los Pirineos. Actas (Cervera), 359-374.

Presedo Velo, F. J., y Caballos Rufino, A. (1988): «La ciudad de Carteia: estado de la cuestión y primeros resultados de la campaña de 1985». En Actas 1er Congreso Peninsular de Historia Antigua. Vol. II (Santiago de Compostela), 509- 519. 
Richardson, J. S. (1998): Historia de España II. Hispania y los Romanos. Madrid.

Roddaz, J.-M. (1988): "Guerres civiles et romanisation dans les vallées de l'Ebre". En Hommages á Robert Étiénne (Paris), 317-338.

Rodriguez NeILA, J. F. (1988): Historia de Córdoba I. Del amanecer prehistórico al ocaso visigodo. Córdoba.

ROLDAN GOMEZ, L. et alii (1998): Carteia. Madrid.

RoldÁN HeRvas, J. M. (1972): “El elemento indígena en las guerras civiles en Hispania: Aspectos sociales". HAnt2, 77-123.

Roldán Hervas, J. M. (1974): Hispania y el ejército romano. Contribución a la historia social de la España Antigua. Salamanca.

Roldán Hervas, J.M. (1978a): "La guerra civil entre César y Pompeyo (49-31 a.C.). En Historia de España Antigua, II. Hispania romana (Madrid), 155-173.

Roldan Hervás, J. M. (1978b): "Las provincias hispanas en la era de Pompeyo". En Historia de España Antigua II. Hispania Romana (Madrid), 141-153.

Romanelli, P. (1959): Storia delle province romane dell'Africa. Roma.

Rossı, R. F. (1953): “Anticesariani d'Oriente e d'Occidente". Maia 6, 283-301.

SalinAS de Frias, M. (1983): "La función del hospitium y la clientela en la conquista y romanización de Celtiberia", SHHA 1, 21-41.

Salinas de Frias, M. (1986): Conquista y romanización de la Celtiberia. Salamanca.

Salinas dE Frias, M. (1996): El gobierno de las provincias hispanas durante la República Romana (218-27 a. C.). Salamanca.

SÁNCHEZ-AlboRnOz, C. (1949): "Proceso de la romanización de España desde los Escipiones hasta Augusto". AHAM 4, 5-35.

Sayas Abengoechea, J. J. (1989): "Los pactos de hospitalidad de Pompaelo en el contexto de los pactos de la Península Ibérica", en El solar vascón en la antigüedad. Cuestiones de lengua, arqueología, epigrafia e historia, VII. Cursos de verano en San Sebastián (San Sebastián), 95-125.

Schulten, A. (1940): Fontes Hispaniae Antiquae V. Las guerras de 72-19 a. de J.C. Barcelona.

SCUDERI, R. (1989): "Significato politico delle magistrature nelle cittè italiche del I sec. a.C.". Athenaeum, 67, 117-138.

SEAR, R. S. (1998): The History and Coinage of Roman Imperators, 49-27 BC. London.

Shackleton-Balley, D. R. (1966): Cicero's Letters to Attcus Volumen V. 48-45 B. C. 211-354 (Books XI to XIII). Cambridge.

Solana SaINZ, J. M. (1989): “Colonización y Municipalización bajo César y Augusto". En Aspectos de la colonización y municipalización de Hispania (Mérida), 71-106.

Solana Sainz, J. M., y Montenegro Duque, A. (1986): “César en Hispania y la guerra civil con Pompeyo". En Historia de España 3. España romana (Madrid), 120-142.

SYME, R. (1989): La revolución romana. Madrid.

TAYLOR, L. R. (1949): Party Politics in the Age of Caesar. Berkeley.

ThOUVEnOt, R. (1973): Essai sur la province romaine de Bétique. Paris.

Tovar, A. (1989): Iberische Landeskunde. Segunda Parte. Las tribus y las ciudades de la antigua Hispania. Tomo 3. Tarraconensis. Baden-Baden.

Tovar, A. y Blázouez, J. M. (1975): Historia de la Hispania romana. La Península lbérica desde 218 a.C. hasta el siglo v. Madrid.

Tranoy, A. (1981): La Galice romaine. Recherches sur le nord-ouest de la péninsule ibérique dans l'Antiquité. Paris.

TSIRKIN, Ju. B. (1981): "The south of Spain in the civil war of 40-45 B.C." AEspA 54, 91-100.

TSIRKIN, Ju. B. (1993): “Romanization of Spain: socio-political aspects (II). Romanization on the period of the Republic". Gerión 11, 271-312.

VILLARONGA, L. (1979): Numismática antigua de Hispania. Iniciación a su estudio. Barcelona.

WEICH, K. E. (1995): "The Career of M. Aemilius Lepidus in 49-44 B.C.». Hermes 123, 443-454.

WILSON, A. J. N. (1966): Emigration from Italy in the Republican Age of Rome. Manchester. 